\title{
Field Measurement and Numerical Simulation of the Relationship Between Vertical Wind Environment and Building Morphology in Residential Areas in Xi'an, China
}

\author{
Wei Feng \\ Xi'an Jiaotong University \\ Meng Zhen \\ Xi'an Jiaotong University \\ Wei Ding ( $\square$ wayneding7@163.com ) \\ Xi'an Jiaotong University https://orcid.org/0000-0002-8292-0681 \\ Qishu Zou \\ Xi'an Jiaotong University
}

\section{Research Article}

Keywords: Vertical wind environment, unmanned aerial vehicle measurement, numerical simulation, static wind area

Posted Date: May 13th, 2021

DOI: https://doi.org/10.21203/rs.3.rs-438680/v1

License: (c) (i) This work is licensed under a Creative Commons Attribution 4.0 International License. Read Full License

Version of Record: A version of this preprint was published at Environmental Science and Pollution Research on September 20th, 2021. See the published version at https://doi.org/10.1007/s11356-021$16522-6$. 


\section{Field measurement and numerical simulation of the relationship}

2 between vertical wind environment and building morphology in

3 residential areas in $\mathrm{Xi}$ 'an, China

Wei Feng ${ }^{\mathrm{a}}$, Meng Zhen ${ }^{\mathrm{b}}$, Wei Ding ${ }^{\mathrm{b}, *}$, Qishu Zou ${ }^{\mathrm{b}}$

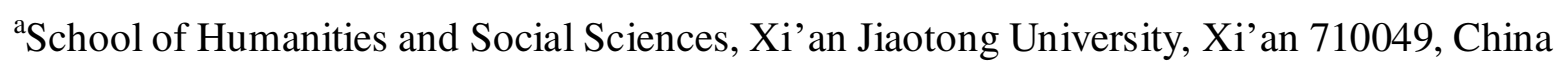
${ }^{b}$ Department of Architecture, School of Human Settlements and Civil Engineering, Xi' an Jiaotong University, Xi' an 710049, China Corresponding author: Wei Ding, wayneding7@163.com Abstract: The inadequate consideration of the impact of building morphology on ventilation efficiency in many urban residential areas has resulted in a series of environmental problems that threaten human health. The purpose of this paper is to establish a prediction model between ventilation efficiency and building forms in residential areas. Firstly, the characteristics of vertical wind profile in residential areas are measured through unmanned aerial vehicle (UAV); secondly, the wind speed ratio (WSR) at different height levels under the impact of morphological index (floor area ratio, building density, average building height, enclosure degree, height fall and maximum building height) in the residential area is simulated by ENVI-met; finally, two kinds of prediction formulas are obtained: (1) the average ventilation efficiency at the pedestrian level and (2) the prediction formula of WSR at different heights. The results show that the wind speed (WS) in residential area below $35 \mathrm{~m}$ is about $0.6 \mathrm{~m} / \mathrm{s}$ lower than that in park. The results of numerical simulation show that the mean WSR at the pedestrian level is negatively correlated with each index and the height fall morphological index has the greatest impact on the WSR at different heights. The research can provide a reference for the optimal planning and design of ventilation efficiency of residential buildings, especially those in static wind areas.

Key words: Vertical wind environment; unmanned aerial vehicle measurement; numerical simulation; static wind area 
Nomenclature:

UAV__ Unmanned Aerial Vehicle

FAR_—Floor Area Ratio

BD_Building Density, \%

$\mathrm{ABH} \_$_ Average Building Height, $\mathrm{m}$

ED_Enclosure Degree

HF_—Height Fall, m

MBH—-Maximum Building Height

SVF-—Sky View Factor

WS_—Wind Speed, $\mathrm{m} / \mathrm{s}$

WSR_—Wind Speed Ratio

\section{Introduction}

The urbanization of China has been a boost to a large number of urban residential areas, which give rise to many environmental problems while satisfying the housing needs of residents. Insufficient consideration of ventilation efficiency in residential areas will bring adverse impacts on air pollution reduction, high temperature weather mitigation and human

32 thermal comfort, or even cause the spread of epidemics (Feng W, 2020; Hong B, 2015;

33 Mochida A, 2008; Vazquez-Prokopec G M, 2010; N. E. Yuan C, Norford L K. , 2014). Urban

34 residents generally spend more than $2 / 3$ of their time in residential area (State bureau of 35 technical supervision, 2018). It is therefore of great significance to enhance the ventilation 36 efficiency in residential areas for residents' health and quality of life (State Bureau of 37 Technical Supervision, 2018). 
The previous studies on residential wind environment were carried out from two aspects: planning and layout, and building morphology. Some scholars discussed the correlation between building layout and ventilation efficiency of residential area. Asfour et al. simulated the wind field of different types of residential area layout by CFD. The results showed that the residential buildings arranged around a central space, forming a layout open to the prevailing wind, can make the residential area well-ventilated (S., 2010). Some scholars also paid attention to the relationship between building morphology index and ventilation efficiency of wind environment. Kubota et al., for example, found a striking correlation between BD and the WSR at mean pedestrian level from wind tunnel test results of 22 Japanese urban residential areas (M. M. Kubota T, Tominaga Y, et al. 1699-1708., 2008). Yang et al. measured the wind environment of 10 high-rise residential areas in central Shanghai. They found that the ventilation efficiency in the pedestrian area is significantly related to the ED of the buildings and the green space, and that a 10\% increase in SVF can raise the WSR by 7\% 8\% (Yang F, 2013). Li et al. studied the correlation of the FAR with the ventilation efficiency of residential areas, and reported that when the FAR rises from 0.63 to 2.32 , the mean WSR of residential area declines by 0.18 ( $\mathrm{Li} \mathrm{L}, 2018)$. This paper mainly discusses the influence of building morphology index on ventilation efficiency of residential areas, from pedestrian height and vertical direction.

The previous studies mostly focused on the impact of building morphology factors on ventilation efficiency at the pedestrian height (Du Y, 2017; Jones P J, 2004; Mittal H, 2019; To A P, 1995), few of them investigated the impact in the vertical direction. Some scholars have explored the wind profile on the urban scale. As early as 1981, Landsberg and Helmut proposed that the roughness of the city would affect the surface resistance, WS and the wind profile of the city (E., 1981). Edward et al., after taking the dense urban morphology and the impact on the wind field into consideration, made a high-resolution map of Hong Kong's urban surface roughness using the mapping method, which provided guidance for urban planning (Ng E, 2011). Liu et al. constructed a full-scale urban model with a length of 2-20 $\mathrm{km}$, simulated the urban wind flow via RANS (Reynolds average Navier-Stockes) equation, and compared the differences of wind profiles in the vertical direction with and without building details (Liu S, 2017). In fact, most of the recent relevant research regarding wind 
environment is conducted on the urban scale, or from pedestrian level, and few research focuses on the vertical wind environment on the residential area scale.

The purpose of this paper is to investigate the relationship between the design index of residential buildings and the ventilation efficiency. The research mainly includes the following aspects: 1) to compare the difference of wind profile between open area and residential area in the city; 2) to explore the coupling mechanism between the ventilation efficiency and the building morphology of residential area at different heights; 3 ) to establish a prediction model in residential area at different heights. This paper can provide reference for improving the ventilation efficiency of residential areas, especially those in low WS cities and regions.

\section{Methodology}

\subsection{Field measurements}

Xi' an City $\left(107.40-109.49^{\circ} \mathrm{E}, 33.42-34.4^{\circ} \mathrm{N}\right)$ is located in Guanzhong Basin in the middle of Weihe River Basin. Xi'an has a warm semi humid continental monsoon climate with distinct four seasons and relatively dry air (Jin LN, 2014). The annual dominant wind direction in $\mathrm{Xi}$ an is $67.5^{\circ}\left(0^{\circ}\right.$ is the north, $90^{\circ}$ is the east), the frequency is $11 \%$, the static wind $(0-0.2 \mathrm{~m} / \mathrm{s})$ frequency is $35 \%$, the outdoor mean WS in summers is $1.9 \mathrm{~m} / \mathrm{s}$, and the outdoor mean WS in winters is $1.4 \mathrm{~m} / \mathrm{s}$ (Ministry of housing and urban-rural development, 2012). Located in area with a typical low WS, Xi' an is facing great challenges in air pollution, heat island effect and other issues.

In this paper, an open park and a typical residential area in $\mathrm{Xi}$ ' an are selected to compare the differences of near surface wind profiles of different land use types. The measurement time was on August 13, 2017, and the relevant information of the measurement points is given in Table 1.

Table 1 Location of field measurements

\begin{tabular}{c|c|c|c}
\hline $\begin{array}{c}\text { Climatic } \\
\text { region }\end{array}$ & City & Measured location & Scene photos \\
\hline
\end{tabular}




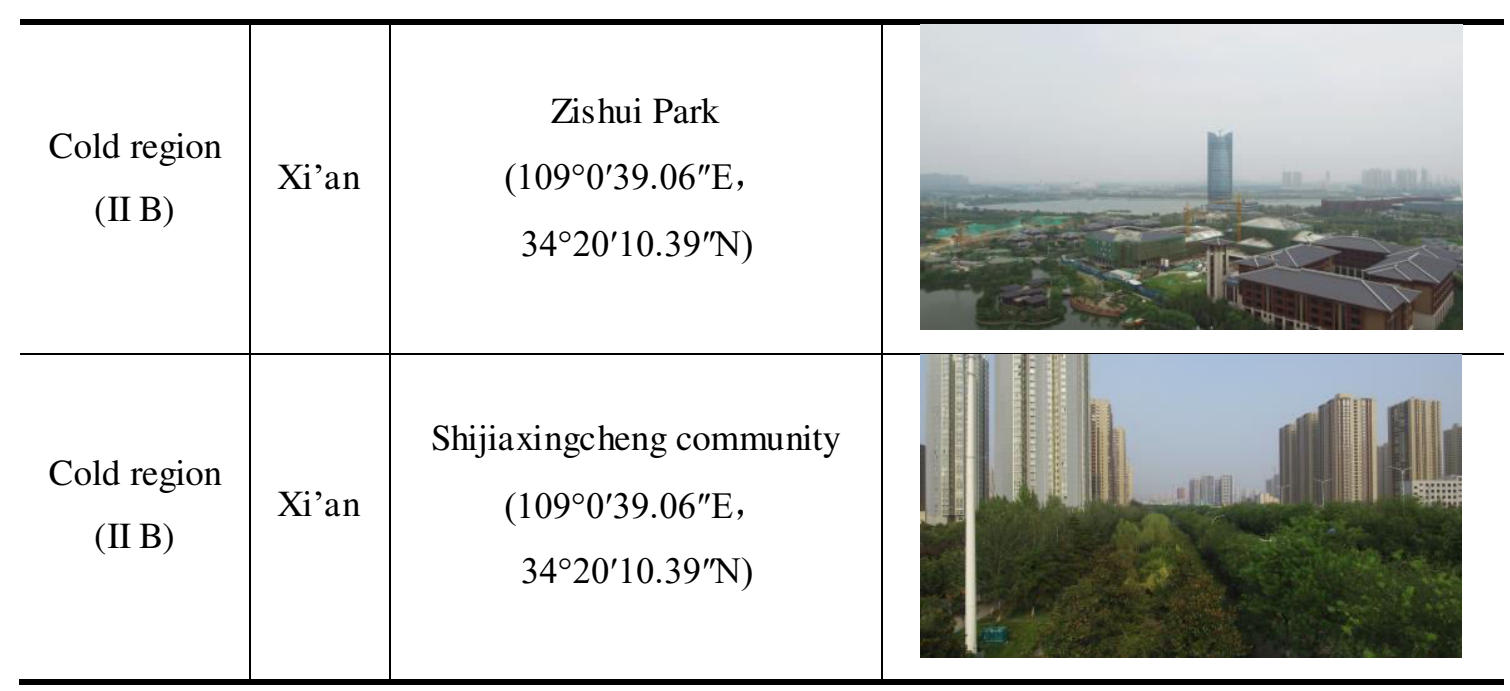

The vertical WS in the residential area was measured by a drone (model: Dajiang M600

94 UAV). The UAV is equipped with a two-dimensional ultrasonic anemometer namely Decagon

95 DS-2 (accuracy: $0.30 \mathrm{~m} / \mathrm{s}$ or $<3 \%$; range: 0 to $30 \mathrm{~m} / \mathrm{s}$; resolution: $0.01 \mathrm{~m} / \mathrm{s}$ ) (Figure 1 ).

The wind data of the vertical wind environment were measured by the test equipment

97 carried by the UAV at typical points in the selected area within a height range of $1.5-100 \mathrm{~m}$, 98 and the data were collected through a 5 min hovering every 10 meters. The vertical wind profiles of residential area and park were tested.

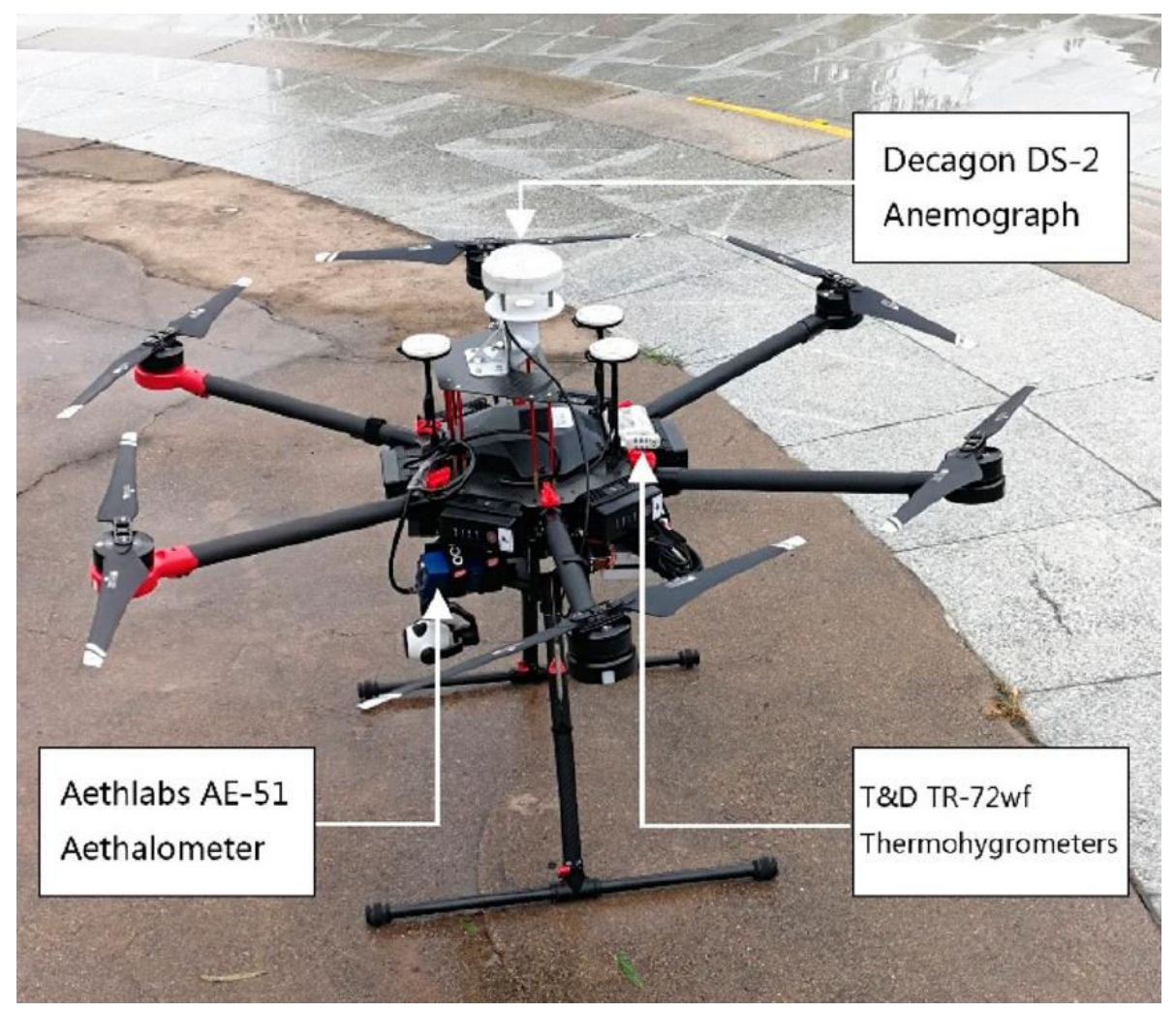

Figure 1 UAV and test equipment (Zhen M, 2019) 
In order to evaluate and compare the wind environment in various scenes, the WSR

101 index is used to evaluate the ventilation efficiency in residential areas at different heights (FL.,

102 2005; Ren Chao, 2017).

$$
\mathrm{VRw}=\frac{V_{p}}{V_{\infty}}
$$

$103 \quad V_{\infty}$ is the wind speed at the top of the boundary layer (where the wind speed is not 104 affected by the urban canopy) in $\mathrm{m} / \mathrm{s}$;

$105 \quad V_{P}$ is the wind speed at a certain height above the ground in $\mathrm{m} / \mathrm{s}$;

106 VRw is the ventilation efficiency at the current level affected by the built-up area.

\subsection{ENVI-met simulation}

The ENVI-met adopted in this paper is a simulation program of urban microclimate developed by Michael Bruce to simulate the wind and thermal environment on a block scale

110 (Bruse, Fleer, \& Software, 1998). In recent years, ENVI-met has been widely verified and 111 applied in the field of urban wind environment (Á., 2013; Jung W S, 2006; Wang Y, 2019).

112 The simulation study is carried out on a typical determinant residential area with a length 113 of $400 \mathrm{~m}$ and a width of $380 \mathrm{~m}$ (Figure 2). On this basis, by altering a single design variable,

114 its impact on the mean WSR of the whole area is compared. Design variables include ABH, $115 \mathrm{BD}, \mathrm{FAR}, \mathrm{ED}, \mathrm{HF}$ and $\mathrm{MBH}$. Table 2 lists the variation range of each design variable. 


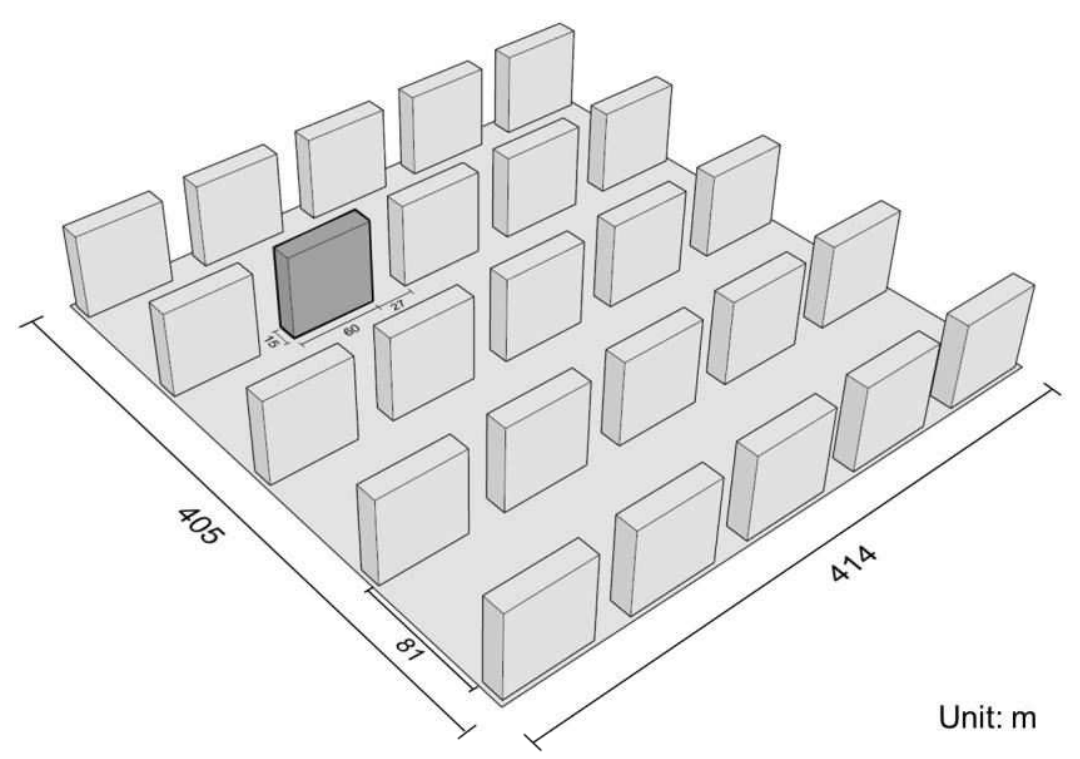

Figure 2 Basic model

Table 2 Range of morphological parameters

\begin{tabular}{c|c|c|c|c|c|c|c|c}
\hline MBH & $30 \mathrm{~m}$ & $40 \mathrm{~m}$ & $50 \mathrm{~m}$ & $60 \mathrm{~m}$ & $70 \mathrm{~m}$ & $80 \mathrm{~m}$ & $90 \mathrm{~m}$ & $100 \mathrm{~m}$ \\
\hline ABH & $10 \mathrm{~m}$ & $20 \mathrm{~m}$ & $30 \mathrm{~m}$ & $40 \mathrm{~m}$ & $50 \mathrm{~m}$ & $60 \mathrm{~m}$ & & \\
\hline HF & $10 \mathrm{~m}$ & $20 \mathrm{~m}$ & $30 \mathrm{~m}$ & $40 \mathrm{~m}$ & $50 \mathrm{~m}$ & $60 \mathrm{~m}$ & $70 \mathrm{~m}$ & \\
\hline FAR & 0.403 & 0.805 & 1.342 & 1.879 & 2.147 & 2.684 & & \\
\hline BD & $4.9 \%$ & $8.7 \%$ & $13.5 \%$ & $24.3 \%$ & $35.6 \%$ & $51.9 \%$ & & \\
\hline ED & 0.092 & 0.276 & 0.378 & 0.568 & & & & \\
\hline
\end{tabular}

The data of air temperature, relative humidity, WS and wind direction on June 21, 2019

118 measured by HOBO U23-001, UAV and on-board equipment are used as input values of the

119 simulation software (such as Table 3). The accuracy of the simulation software is verified by

120 the measured and simulated data of Xi' an finance and economics campus. As shown in Figure

1213 , the average relative error between the measured and simulated WS is $13.5 \%$.

\begin{tabular}{c|c}
\hline Start date & June 21, 2019 \\
\hline Start time & $00: 00$ \\
\hline Simulation time & $48 \mathrm{~h}$ \\
\hline
\end{tabular}




\begin{tabular}{c|c}
\hline Wind speed at $10 \mathrm{~m}$ & $5.3 \mathrm{~m} / \mathrm{s}$ \\
\hline Wind direction $\left(0^{\circ}\right.$ is north) & $67.5^{\circ}$ \\
\hline Air temperature & $18.9 \sim 28.9^{\circ} \mathrm{C}$ \\
\hline Relative humanity & $42.0 \sim 80.0 \%$ \\
\hline
\end{tabular}

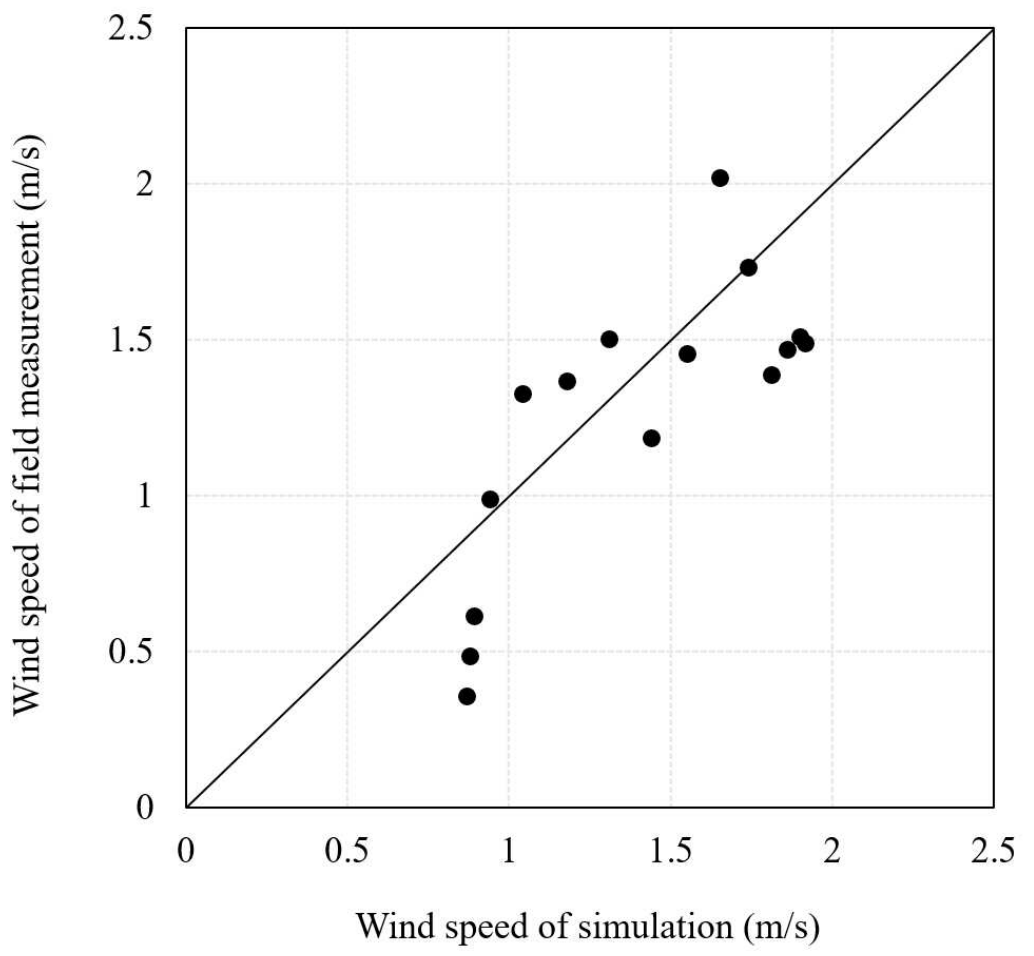

Figure 3 Correlation between measured and simulated results of vertical WS

\section{Results}

$124 \quad 3.1$ Surface wind profile difference between urban built-up area and open area

125 Figure 4 shows the WS distribution characteristics at different heights of Zishui Park. In

126 general, the mean WS increases with the rising height. Specifically, the minimum and

127 maximum of the mean WS measured at the heights of $1.5 \mathrm{~m}$ (the pedestrian level) and $100 \mathrm{~m}$

128 are $1.07 \mathrm{~m} / \mathrm{s}$ and $3.98 \mathrm{~m} / \mathrm{s}$, respectively. From $1.5 \mathrm{~m}$ to $12 \mathrm{~m}$, the WS surges with the rising

129 height, and increases by $2 \mathrm{~m} / \mathrm{s}$ every $10 \mathrm{~m}$ increase in height. At the height of $12 \mathrm{~m}$ to $100 \mathrm{~m}$,

130 the WS increases slowly with the increasing height. The WS increases by $0.01 \mathrm{~m} / \mathrm{s}$ with every

$13110 \mathrm{~m}$ increase in height. This may be attributed to the fact that there are many trees and 
132 artificial facilities in Zishui Park, and these obstacles near the ground slow down the WS.

133 The WS distribution characteristics at different heights of Shijiaxingcheng Community 134 are shown in Figure 5. In general, the mean WS increases along with the height. Specifically, 135 the minimum and maximum of the mean WS measured at the heights of $1.5 \mathrm{~m}$ and $80 \mathrm{~m}$ are $1360.56 \mathrm{~m} / \mathrm{s}$ and $2.56 \mathrm{~m} / \mathrm{s}$, respectively. In the height range of $1.5 \mathrm{~m}$ to $12 \mathrm{~m}$, the WS increases 137 rapidly with the increasing height. Each $10 \mathrm{~m}$ of increase in height raises the WS by $1 \mathrm{~m} / \mathrm{s}$. In 138 the height range of 12 to $36 \mathrm{~m}$, by contrast, the WS dwindles with the rising height. The WS 139 decreases by $0.06 \mathrm{~m} / \mathrm{s}$ for every $10 \mathrm{~m}$ of height increase. In the range of 36 to $100 \mathrm{~m}$, the WS 140 increases slowly with the height, and by $0.19 \mathrm{~m} / \mathrm{s}$ every $10 \mathrm{~m}$ of increase in height.

141 It can be seen that the WS in the residential area below building heights are significantly 142 lower than those in the park area. The mean WS measured below $35 \mathrm{~m}$ in the residential area 143 and park are $1.2 \mathrm{~m} / \mathrm{s}$ and $1.8 \mathrm{~m} / \mathrm{s}$, respectively. Residential buildings reduce WS by about 0.6 $144 \mathrm{~m} / \mathrm{s}$.

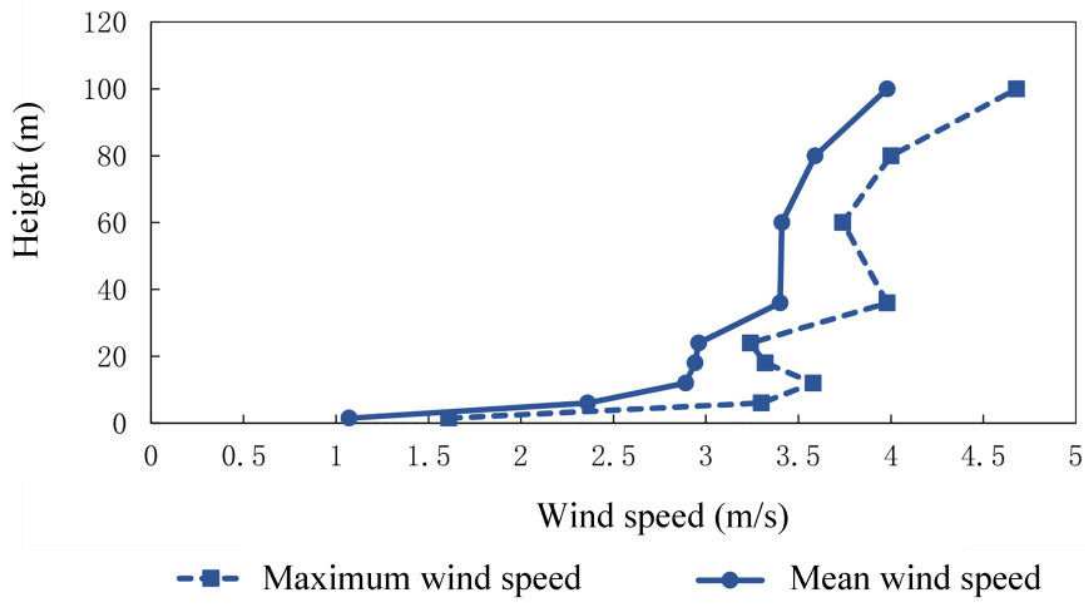

Figure 4 The WS at different heights in Zishui Park in Xi'an 


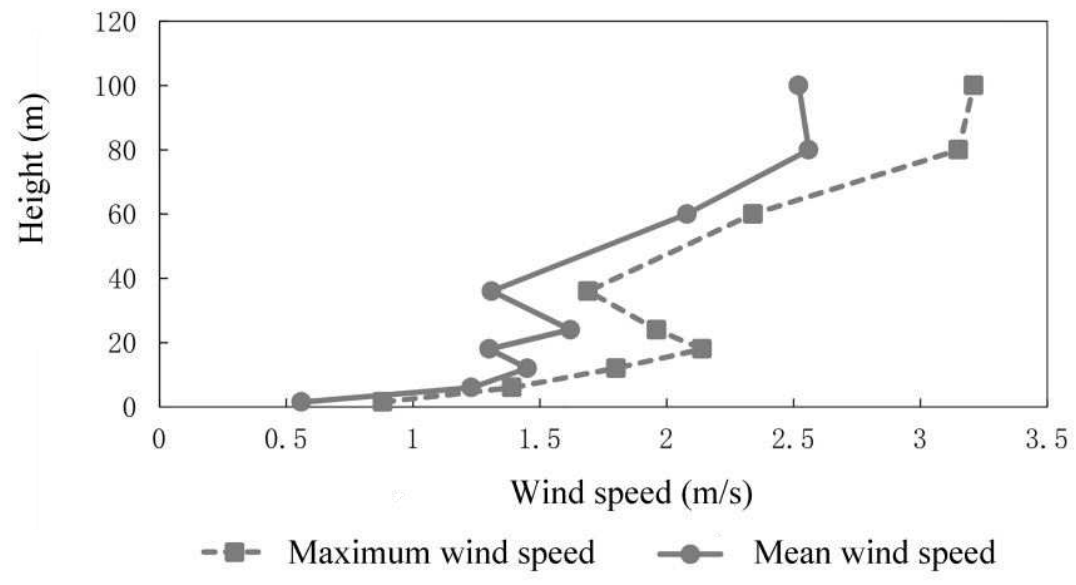

Figure 5 The WS at different heights at Shijiaxingcheng in Xi'an

145 3.2 Single factor correlation between vertical wind environment and morphological index

146 This part will further explore the influence of residential area form on the ventilation

147 efficiency at the pedestrian level and in vertical direction, and summarize the reasons for the 148 difference in vertical wind profile in the residential area through single factor analysis and 149 multi-factor analysis. The results are divided into two parts: the WSR at the pedestrian level $150 \quad(1.5 \mathrm{~m})$ and the vertical WSR at different heights.

\subsubsection{Impact of ABH on WSR}

1) Relationship between WSR and ABH at the pedestrian level

As shown in Figure 6, as the average height rises, the area of low WS region gradually increases. Specifically, when the average height is $10 \mathrm{~m}$, the average horizontal WSR at the pedestrian level reaches the maximum of 0.609 , and then decreases slowly with the increasing $\mathrm{ABH}$. In addition, with the increase of the average height, the maximum WS increases slowly.

157 When the average height is $60 \mathrm{~m}$, the maximum WS reaches $5.87 \mathrm{~m} / \mathrm{s}$, and the minimum WS varies from 0.02 to 0.06 , but its correlation with the average height is small. It can be seen that the ventilation efficiency at the pedestrian level dwindles with the increasing average height, which will lead to the occurrence of accelerated winds. 


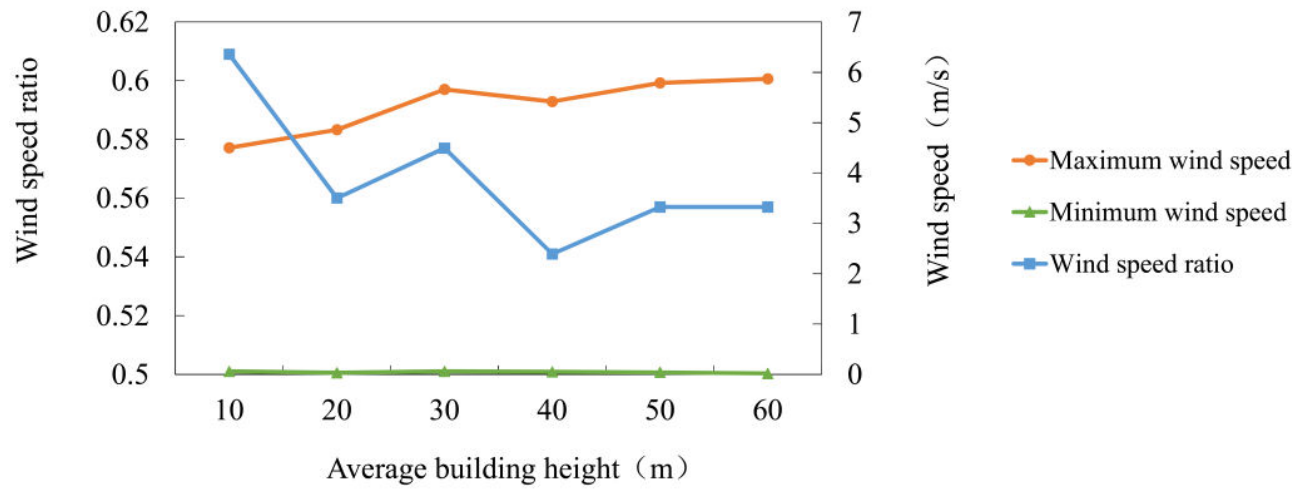

Figure 6 Correlation between mean WSR and ABH

2) Relationship between WSR and ABH at different height levels

As shown in Figure 7, the mean WSR at different horizontal heights increases with the 163 rising height. This indicates that the built-up area obstructs the mean WSR to different degrees.

164 At the same horizontal height, different ABHs have no obvious correlation with the mean 165 WSR, but when the horizontal height is greater than $20 \mathrm{~m}$, the average height exerts a 166 growing attenuation effect on the mean WSR. In the vertical direction, the increase rate of the 167 mean WSR increases with the rising height, showing a trend of first decreasing and then 168 increasing. Specifically, when the mean WSR is below 0.65 , the increase rate of the mean 169 WSR gradually decreases with the increasing height, but after it reaches 0.65 , the increase rate of the mean WSR gradually increases in different scenes.

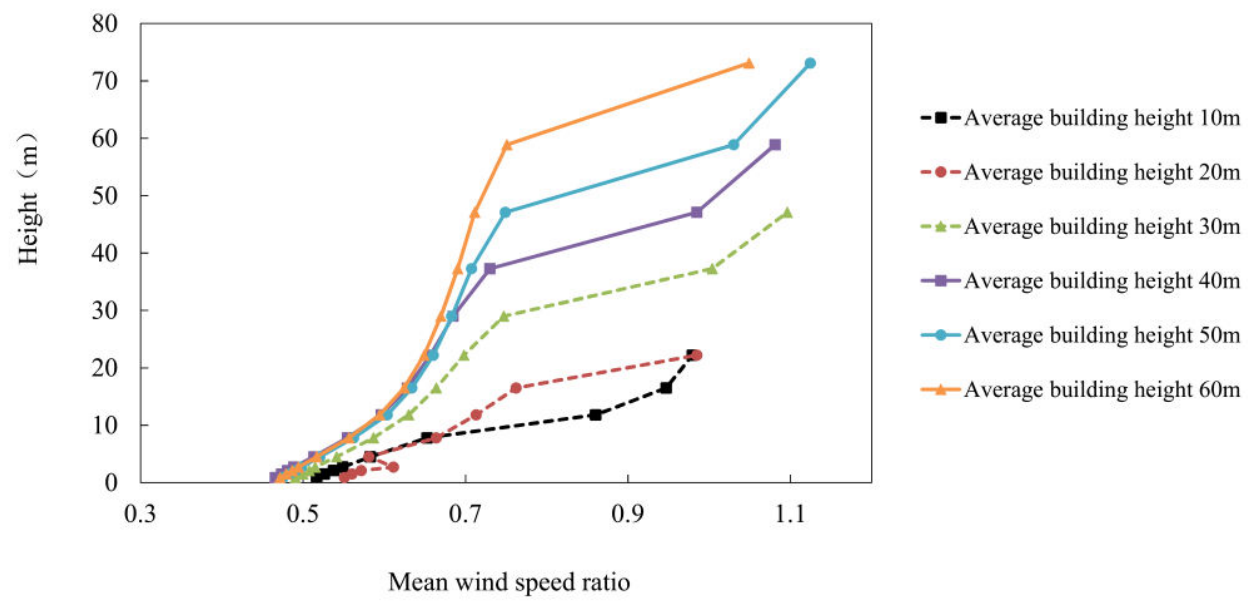

Figure 7 Correlation between the $\mathrm{ABH}$ and the mean WSR in the vertical direction 
1) Relationship between WSR and BD at the pedestrian level

173

As shown in Figure 8, with the increase of BD, the low WS area at the pedestrian height

174 around the building gradually increases, and gradually approaches the static WS. Specifically,

175 when the $\mathrm{BD}$ is $4.9 \%$, the WSR of the average pedestrian height level is 0.592 , which then

176 dwindles with the increasing BD. Moreover, the maximum WS increases along with the BD.

177 When the BD is $51.9 \%$, the maximum WS reaches $5.92 \mathrm{~m} / \mathrm{s}$, and the minimum WS varies

178 between 0.03 and 0.19 , and they are not significantly correlated with the BD. It can be seen

179 that the BD has a negative correlation with the WSR at the average pedestrian height and a

180 positive one with the maximum WS. The increase in BD reduces the ventilation efficiency at

181 the pedestrian height level, and leads to greater WS.

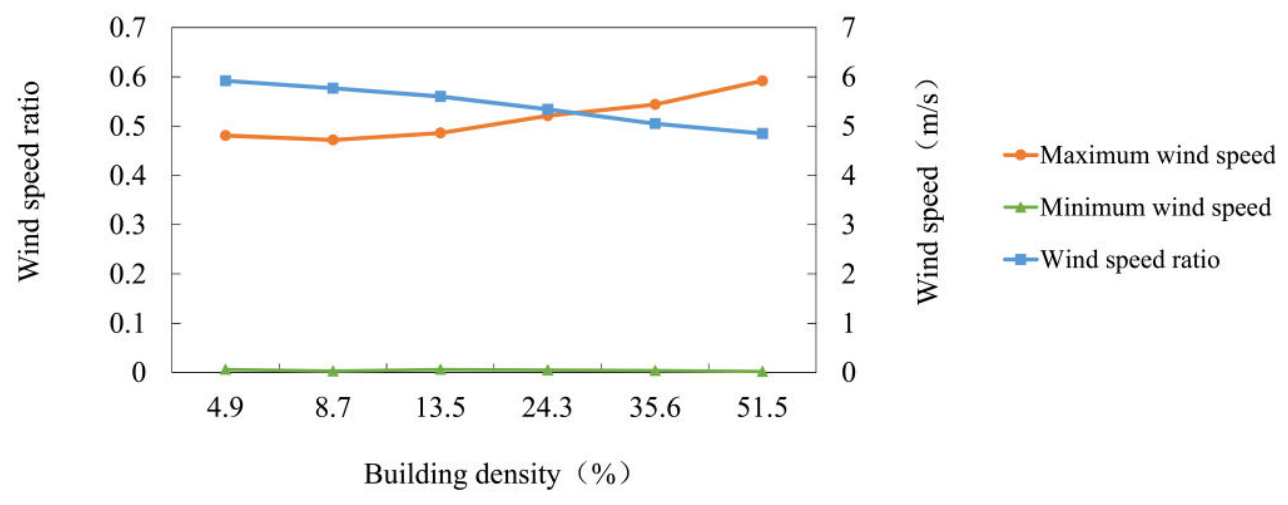

Figure 8 Correlation between the mean WSR at the pedestrian level and BD

182
2) Relationship between WSR and BD at different height levels

It can be seen form Figure 9 that the mean WSR at different horizontal heights increases with the increasing height. At the same horizontal height, the increase rate of the mean WSR below height of $20 \mathrm{~m}$ decreases with the rising BD because the building height is $20 \mathrm{~m}$. Below $20 \mathrm{~m}$, owing to the obstruction of the buildings, the smaller the mean WSR and the denser the built-up area, the greater the obstruction to the wind. When the vertical height is greater than $20 \mathrm{~m}$, the increase rate of the mean WSR has little correlation with the increasing 
$189 \mathrm{BD}$, but in the case of a BD of $51.9 \%$, the increase rate of the mean WSR is the largest. For 190 every $1 \mathrm{~m}$ increase in the vertical height, the mean WSR rises by 0.17 .

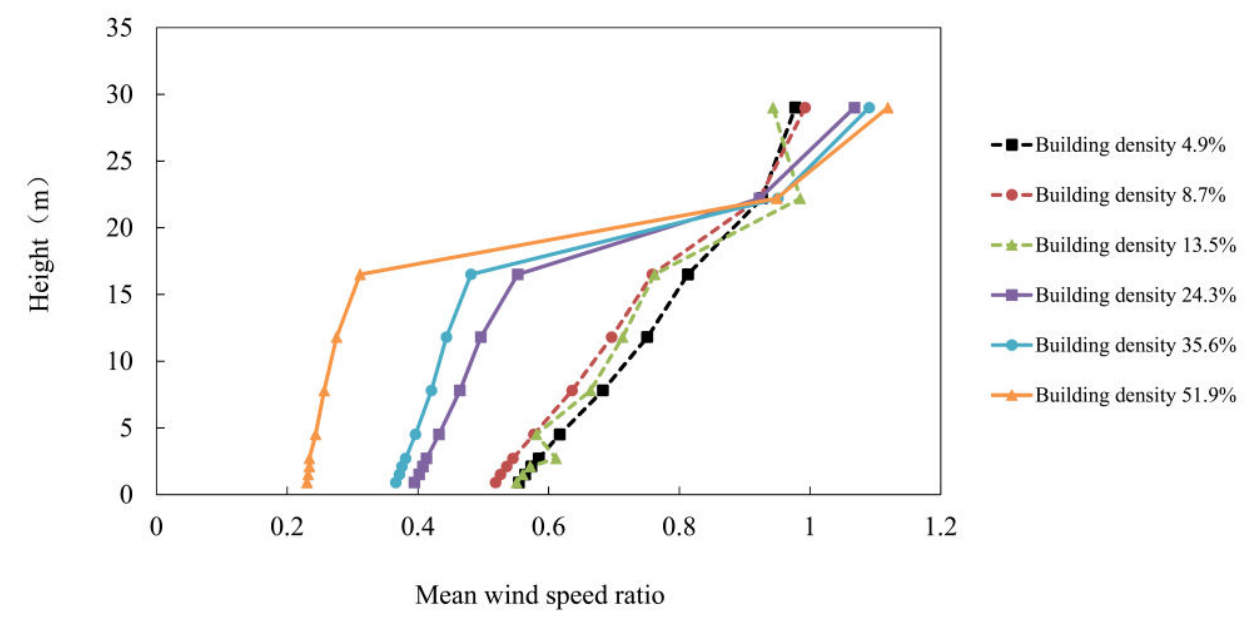

Figure 9 Variation curve between different BD and mean WSR in the vertical direction

\subsubsection{Impact of FAR on WSR}

1) Relationship between WSR and FAR at the pedestrian level

As shown in Figure 10, when the FAR is 0.403 , the mean WSR at the pedestrian level 194 reaches the maximum of 0.609 , and then decreases slowly as the FAR increases. The 195 maximum WS rises with the increasing FAR. When the FAR is 2.684, the maximum WS is $1965.87 \mathrm{~m} / \mathrm{s}$, and the minimum WS changes between 0.02 and 0.06 . Furthermore, with the 197 increase of FAR, the mean WSR at the pedestrian height level gradually declines, which will 198 lead to greater WS.

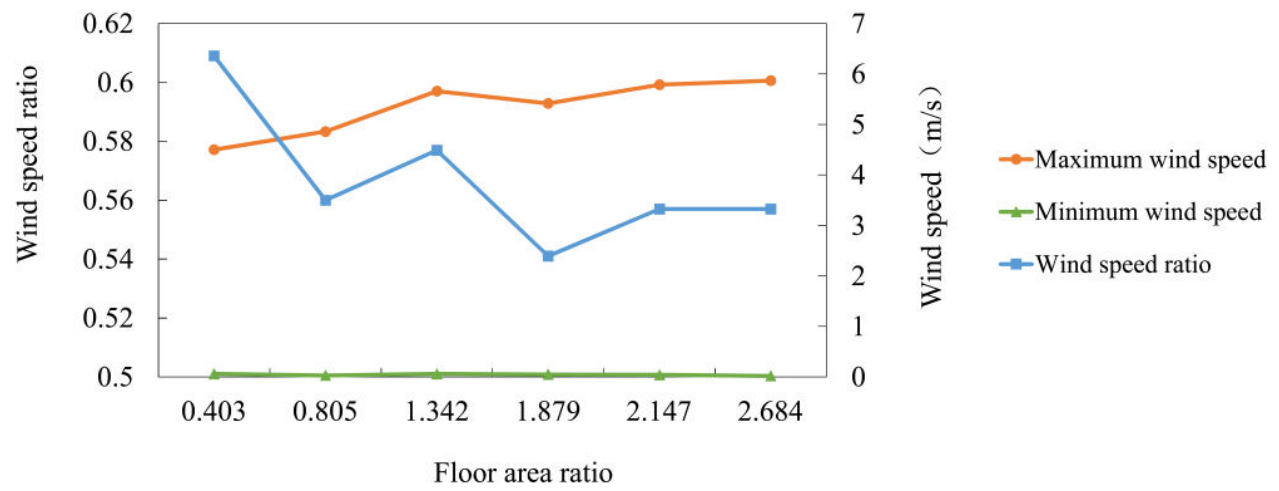


Figure 10 Correlation between mean WSR at the pedestrian level and FAR

199

200

201

202

203

204

205

206

2) Relationship between WSR and FAR at different height levels

As shown in Figure 11, the mean WSR increases along with the vertical height, which indicates that the built-up area on the surface hinders the WS. On the one hand, at the same height level, the correlation between different FARs and the mean WSR is slight. On the other hand, the mean WSR decreases first and then increases with the change of height. When the mean WSR is below 0.7 , the increase rate of the mean WSR decreases with the rising height. But after the mean WSR reaches 0.7 , the increase rate of the mean WSR in different FAR scenarios rises gradually with the vertical height.

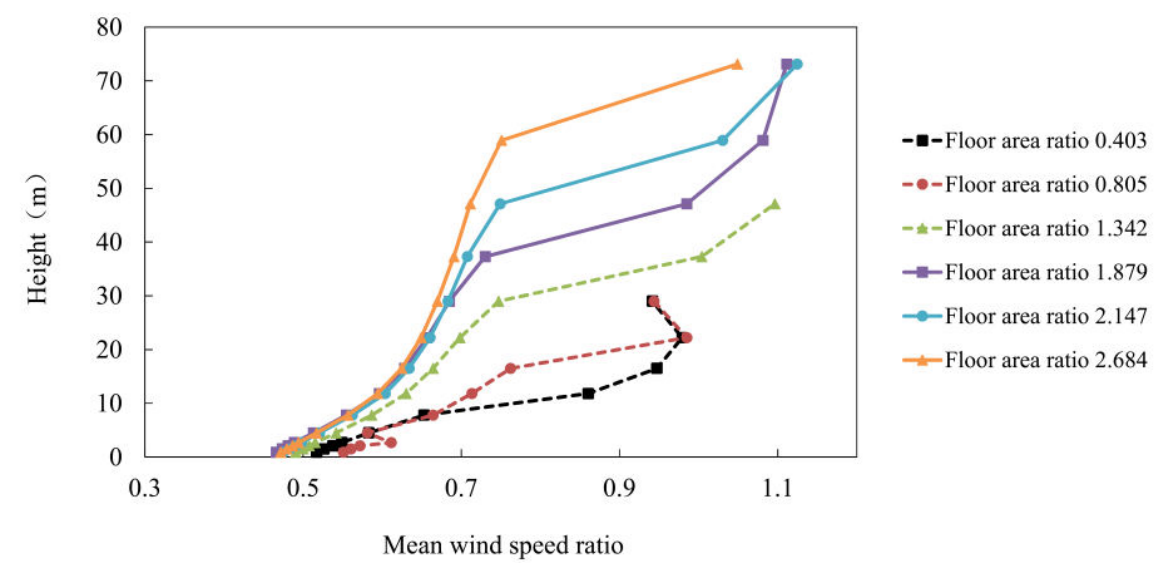

Figure 11 Correlation between the change of FAR with the average height and the mean WSR

\subsubsection{Impact of ED on WSR}

1) The relationship between mean WSR and the ED at the pedestrian level

As shown in Figure 12, as the ED rises, the area of low WS in the center of the site increases gradually. Specifically, when the closure is 0.092 , the mean WSR is 0.630 , which

211 then dwindles with the increasing ED. In addition, when the ED is 0.378, the maximum WS

212 drops to the minimum of $5.74 \mathrm{~m} / \mathrm{s}$, and the minimum WS ranges between 0.03 and 0.05 .

213 Furthermore, the ED is negatively correlated with the mean WSR at the pedestrian level,

214 which indicates that the increase in the ED will reduce the ventilation performance at the 
215 pedestrian height level in the residential area.

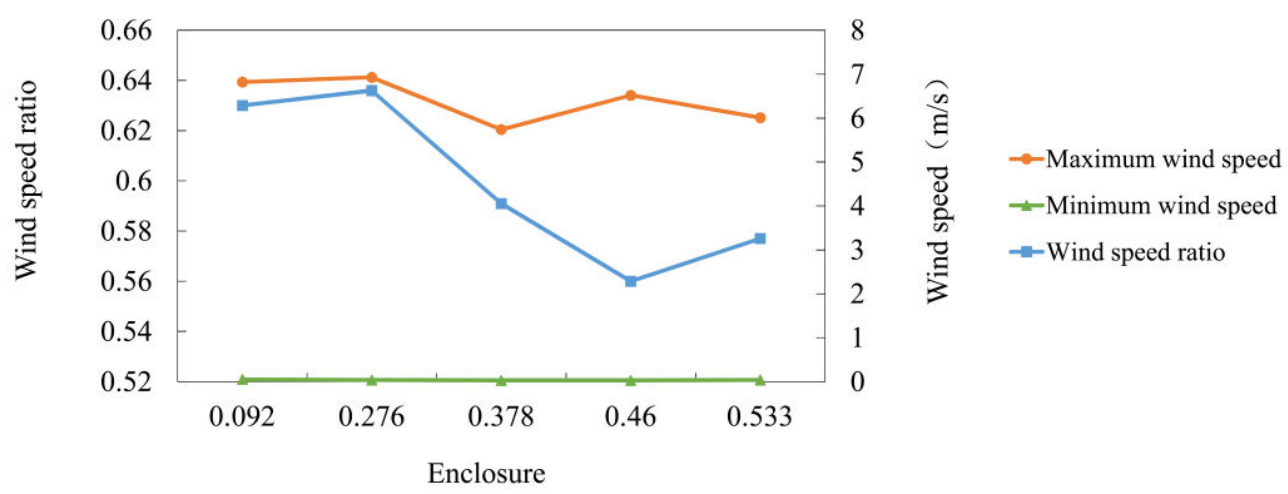

Figure 12 Correlation between the mean pedestrian level WSR and ED

2) Relationship between WSR and ED at different height levels

It can be seen from Figure 13 that the mean WSR of each scene increases along with the 218 vertical height. When the vertical height is smaller than $30 \mathrm{~m}$, at the same horizontal height, 219 the larger the ED, the smaller the mean WSR. In the vertical direction, the increase rate of the mean WSR declines with the increasing ED. The increase rate of the mean WSR is the largest 221 at the ED of 0.092 . When the vertical height increases by $1 \mathrm{~m}$, the increase rate of the mean WSR is about 0.0104 and it is the smallest when the ED is 0.533 . Every $1 \mathrm{~m}$ increase in the vertical height raises the mean WSR by about 0.00775 . Under $30 \mathrm{~m}$, the larger the $\mathrm{ED}$, the greater the wind blocking effect of the scene. The increase in ED will lead to a general reduction in the ventilation efficiency around residential buildings.

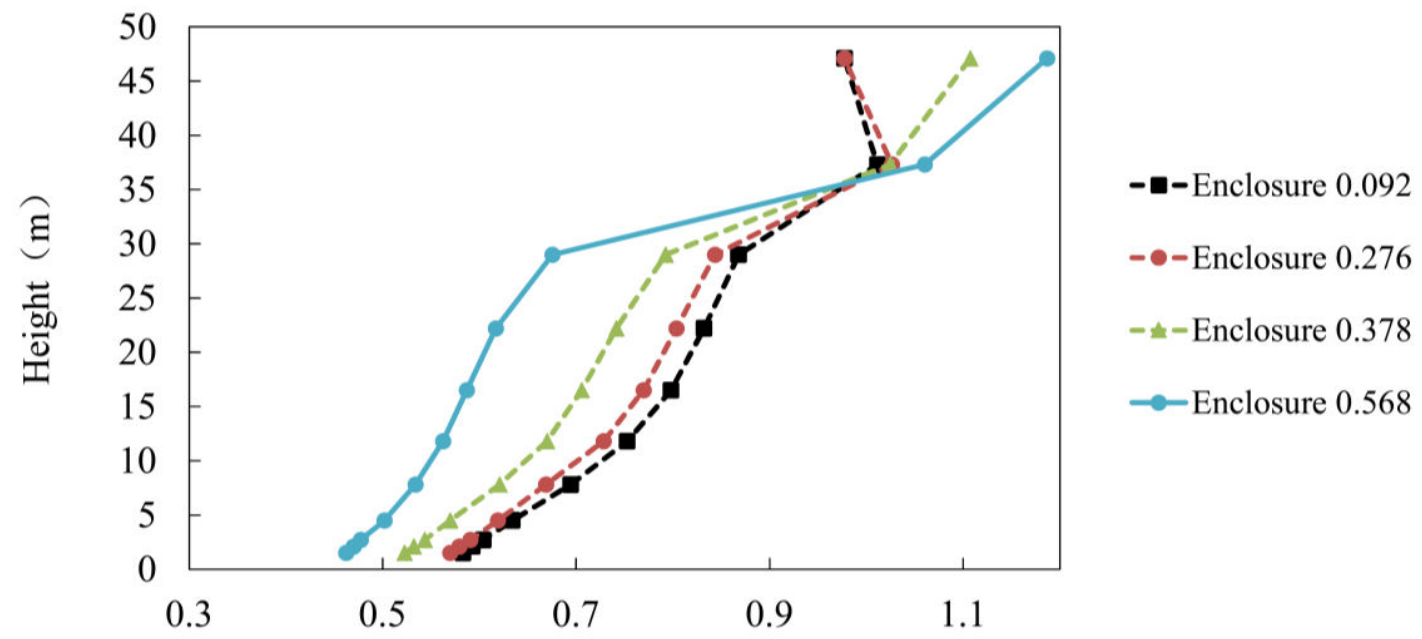

Mean wind speed ratio 
Figure 13 Correlation between the mean WSR and different EDs in the vertical direction

226

227

228

229

230

231

232

233

234

235

236

\subsubsection{Impact of HF on WSR}

1) Relationship between the mean WSR and HF at the pedestrian level

As shown in Figure 14, mean WSR decreases with the rising HF at the pedestrian level. When the HF is 10 , the ratio of mean WS at the pedestrian height level is 0.560 , which then decreases slowly with the increasing HF. The maximum WS increases slowly with the rising HF. When the HF is 70 , the maximum WS reaches the maximum of $5.57 \mathrm{~m} / \mathrm{s}$, and the minimum WS always ranges between 0.03 and 0.09 , showing a descending trend. It can be seen that the HF has a negative correlation with the mean WSR at the pedestrian level and the minimum WS of the site, and a positive relationship with the maximum WS of the site. It shows that the construction of high-rise residential buildings will reduce the ventilation efficiency at the pedestrian level, and result in high WS.

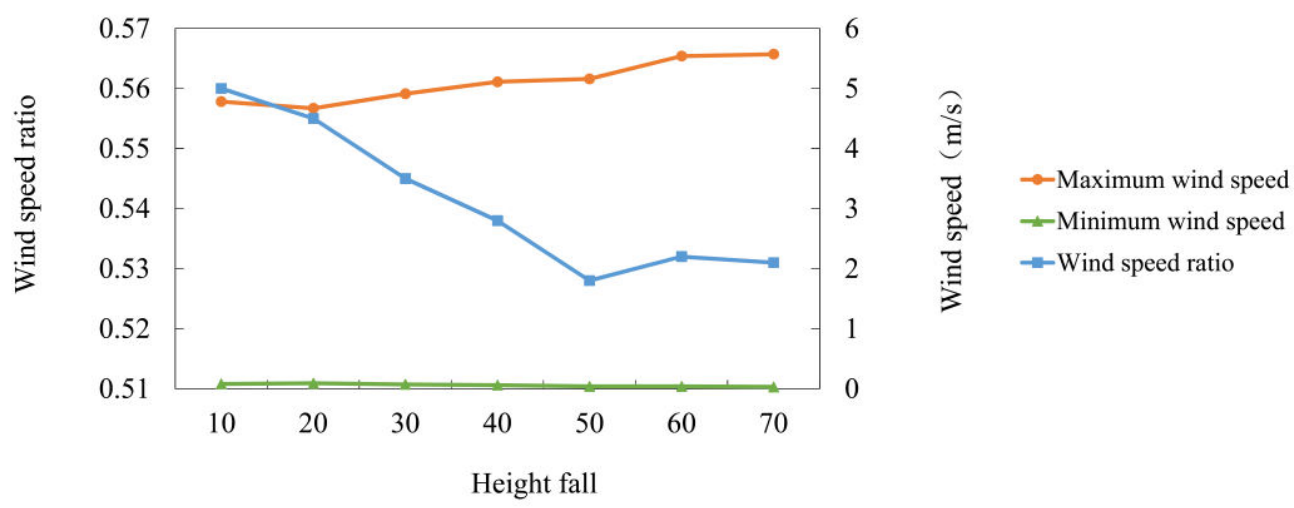

Figure 14 Correlation between the mean WSR at the pedestrian level and HF

Figure 15 shows that the mean WSR of each scene increases with the rising vertical height, except for the scene with a HF of $10 \mathrm{~m}$. When the vertical height is below $20 \mathrm{~m}$, the correlation between different HF and the mean WSR at the same horizontal height is weak. For every $1 \mathrm{~m}$ increase in vertical height, the mean WSR corresponding to different HF increases by about 0.018 . When the vertical height is greater than $20 \mathrm{~m}$, the increase in the HF 
243 will cause a reduction in the mean WSR. When the HF is 70 , the increase rate of the mean

244 WSR is the largest. Each $1 \mathrm{~m}$ increase in the vertical height will lead to an increase of 0.0027

245 in the mean WSR. The possible reason is that the wind is hindered by four high-rise buildings.

246 It is thus can be concluded that the variation of the HF impacts the mean WSR mostly in the 247 area above the average height of the site. The larger the HF, the more obvious the blocking 248 effect of high-rise buildings on the wind.

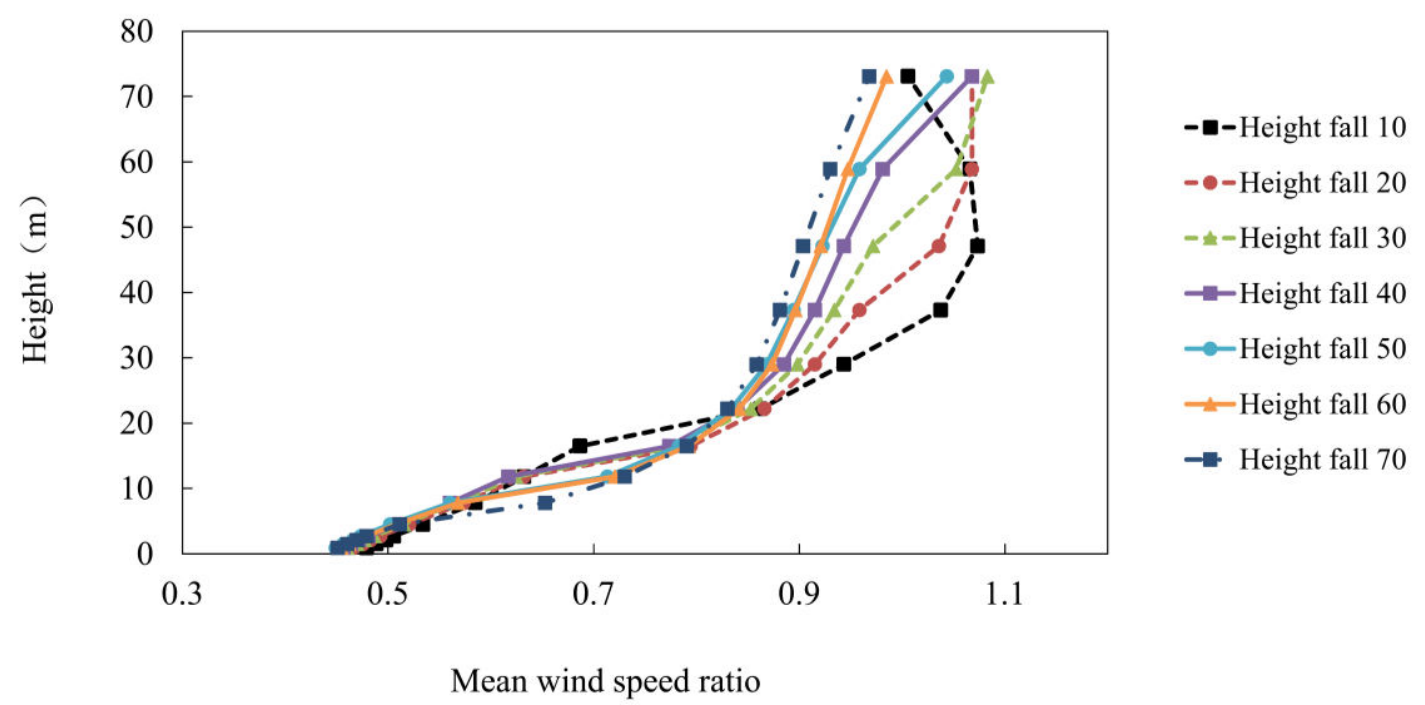

Figure 15 Correlation between the mean WSR and different HF in the vertical direction

1) Relationship between mean WSR and MBH at the pedestrian level

It can be seen from Figure 16 that with the increasing $\mathrm{MBH}$, the area of the low WS 252 region gradually increases, and so does the area affected by the high speed winds around the 253 highest building. Specifically, when the MBH is $30 \mathrm{~m}$, the mean WSR at the pedestrian level 254 is 0.560 , which then dwindles with the rising maximum height. The maximum WS first 255 decreases from 4.71 to $4.42 \mathrm{~m} / \mathrm{s}$, then slowly to $4.97 \mathrm{~m} / \mathrm{s}$, during which the minimum WS 256 varies from 0.03 to 0.08 . Conclusions can thus be drawn that the $\mathrm{MBH}$ has a negative 257 correlation with the mean WSR at the pedestrian level, while has little correlation with the 258 maximum WS or the minimum WS. 


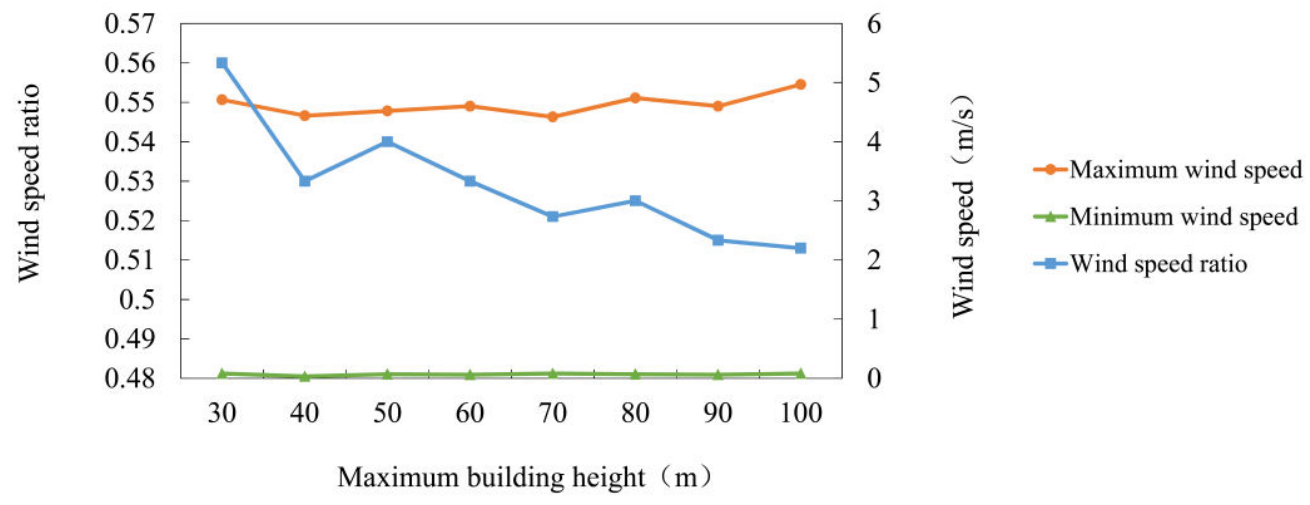

Figure 16 Correlation between the mean WSR at the pedestrian level and MBH

2) Relationship between WSR and MBH at different height levels

Figure 17 shows that, in general, the mean WSR of each scene increases along with the vertical height, and the correlation between the maximum height and the mean WSR is weak

262 at any horizontal height. When the vertical height is below $20 \mathrm{~m}$, the increase rate of the mean

263 WSR in different scenes tends to be equal. For every $1 \mathrm{~m}$ increase in the vertical height, the 264 mean WSR of each scene increases by about 0.014 . When the maximum height is $100 \mathrm{~m}$, the mean WSR is relatively large. When the vertical height is above $20 \mathrm{~m}$, the correlation of the maximum height with the mean WSR is weak. When the maximum height is $80 \mathrm{~m}$, the increase rate of the mean WSR is the lowest. Every $1 \mathrm{~m}$ increase in vertical height raises the mean WSR by about 0.012 . Thus, there is no significant correlation between the maximum height and the mean WSR, and the ABH of the site is the dividing line that affects the change rate of the mean WSR in the vertical direction. 


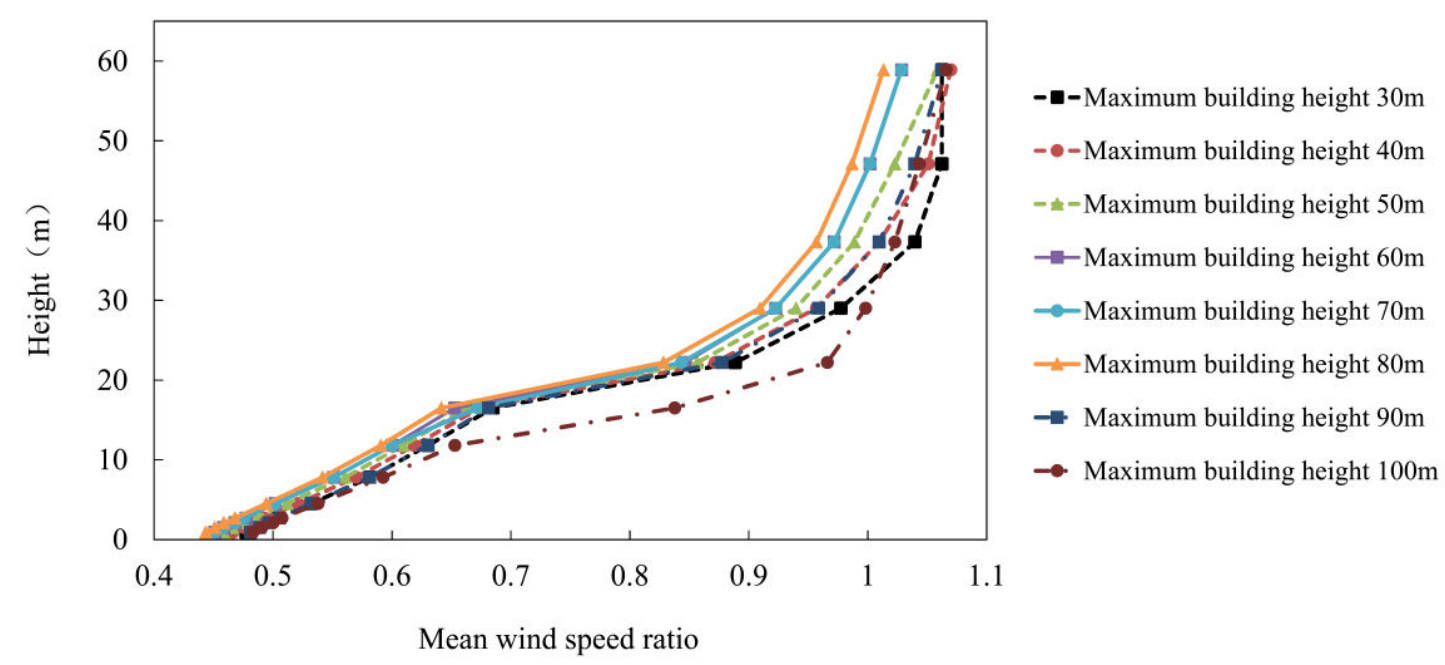

Figure 17 Correlation between the MBH and the mean WSR of different sites in the vertical direction

3.3 Multi-factor correlation between vertical wind environment and morphological index

The single factor analysis of wind environment in residential area is insufficient.

273 Therefore, based on the previous sections, the prediction formulas for the mean WSR at the 274 pedestrian level and vertical wind environment are established respectively.

1) Multiple linear regression formula for WSR at the pedestrian level

The results of the 37 scenarios simulated aboves are integrated (According to Table 2), and the regression equation of the average pedestrian horizontal mean WSR is obtained through SPSS software. Due to the differences in the order of magnitude and unit of each index, the following regression equation and $\mathrm{R}^{2}$ are finally obtained by standardizing the data:

In formula (1), U1 is the mean WSR at the pedestrian level in the residential area under the specific form combination, $\mathrm{ABH}$ is the $\mathrm{ABH}, \mathrm{FAR}$ denotes the FAR, $\mathrm{BD}$ is the $\mathrm{BD}, \mathrm{E}$ is the $\mathrm{ED}$ of the residential area, $\mathrm{HF}$ is the $\mathrm{HF}$, and $\mathrm{MBH}$ is the $\mathrm{MBH}$. It can be seen that $\mathrm{R}^{2}$ is 0.855, indicating that the sample regression effect is good; $F$ test statistic $f=28.565$, and associated probability $\mathrm{p}<0.001$, which indicates that there is a linear regression relationship

286 between the independent variable and the dependent variable; the independent variables with an associated probability p below 0.05 include average height $(\mathrm{P}<0.013)$, BD $(\mathrm{P}<0.001)$, 
HF $(\mathrm{P}<0.005)$ and maximum height $(\mathrm{P}<0.015)$. This implies that the WSR at the pedestrian level has a significant linear relationship with the average height, BD, HF and the maximum height. The influence degree of each index in descending order is as follows: the HF $>$ the $\mathrm{MBH}>$ the $\mathrm{ABH}>$ the $\mathrm{BD}>$ the $\mathrm{FAR}>$ the $\mathrm{ED}$.

2) Multiple linear regression formula for vertical WSR prediction

The simulation results of the above 381 scenarios are taken as the basic data and standardized to obtain the following regression equation and $\mathrm{R}^{2}$ :

$$
\begin{gathered}
\mathrm{U} 2= \\
0.883 \mathrm{VH}-0.252 \mathrm{ABH}-0.112 \mathrm{FAR}-0.07 \mathrm{BD}-0.036 \mathrm{E}-0.637 \mathrm{HF}+0.519 \mathrm{MBH}\left(\mathrm{R}^{2}=\right. \\
0.801)(2)
\end{gathered}
$$

In formula (2), U2 is the mean WSR at any horizontal height in the residential area under the specific combination of forms, $\mathrm{VH}$ is the vertical height. It can be seen that the coefficient $\mathrm{R}^{2}$ is 0.801 , which indicates that the regression effect of the sample is good; the statistic of $\mathrm{F}$ test is $\mathrm{f}=212.42$, and the associated probability is $\mathrm{p}<0.001$, indicating that there is a linear regression relationship between the independent variable and the dependent variable. Furthermore, the vertical height $(\mathrm{P}<0.001)$ is the only the independent variable with an associated probability $(\mathrm{p})$ of below 0.05 , which indicates that there is a significant linear relationship between the vertical height and the WSR of any horizontal plane. The relationship between other building shape indexes and vertical WSR is insignificant. The influence degree of each index in decreasing order is: $\mathrm{VH}>\mathrm{HF}>\mathrm{MBH}>\mathrm{ABH}>\mathrm{FAR}>\mathrm{BD}>$ ED.

\section{Discussions}

This paper aims to establish the relationship between ventilation efficiency and building morphology of residential area. The following will be further discussed in combination with

312 relevant research.

313 The present study shows that, the mean WSR at the pedestrian height level has a 314 significant linear correlation with the average height, BD, HF and the MBH. Some scholars 
315 also studied the relationship between the WSR at the pedestrian level and building 316 morphology. Kubota, in a wind tunnel experimental study on the relationship between WS 317 and BD in Japanese detached houses, concluded that the higher the BD, the smaller the mean 318 WSR (M. M. Kubota T, Tominaga Y, et al, 2008). As in the case study of Feng et al., the WSR at the pedestrian level is negatively correlated with the average height (Feng W, 2020). Yang et al. found that the increase in ED is not conducive to the diffusion of air pollutants in the built-up area (Yang J, 2020). The results of this paper also demonstrate that the increase in ED will reduce the ventilation efficiency of residential area, which is not conducive to the air circulation in residential area or blocks. Yang et al. simulated the summer monsoon environment in Xinjiekou area of Nanjing, and through multiple linear regression analysis, found that the WSR at the pedestrian level has a negative correlation with BD and ED, but a significant, positive linear correlation with average height (Yang, 2016). Nonetheless, the results of this study show that the mean WSR at the pedestrian level will decrease the increasing average height because of the blocking of wind by the buildings. This may be ascribed to the different building geometries, building densities, building intervals, WS and directions adopted in Yang's simulation and this study. Adamek et al. pointed out that the presence of high-rise buildings in urban space will increase the near-surface WS (Adamek K, 2017). It can be concluded that the WSR at the pedestrian height level is negatively correlated with the $\mathrm{BD}$, the average height and the $\mathrm{ED}$, yet positively related to the $\mathrm{MBH}$. In practice, planners and designers can refer to these research results to improve the safety and comfort of the wind environment in residential areas.

In terms of the vertical wind profile, the single factor analysis results show that the increase in each single indicator of building morphology will lead to the reduction in ventilation efficiency. The results of multi-factor analysis demonstrate that the mean WSR has a significant positive correlation with the vertical height, and an insignificant linear relationship with other building morphology indicators. The relevant studies focus mostly on the scale of city. The research results of Liu et al. proved that the wind profiles in urban center and rural area are quite different, and so are the degrees to which WS increases with the height from the ground (Liu, 2011). Grimmond and Oke et al. reported that the horizontal component of wind profile becomes smaller due to the blocking of urban built-up area 
345 (Grimmond C S B, 1999). In the present study, by observing the shape of the wind profile, it 346 can be seen that the wind in the area with buildings is greatly blocked and the ventilation

347 efficiency is reduced, while the WS in the area without buildings is significantly increased.

348 Yuan et al. studied the ways to improve the ventilation in high-density cities, and by 349 comparing the differences in vertical wind profiles, proposed a strategy to improve the 350 ventilation at the pedestrian level by separating single buildings and reducing the overall building coverage of the site. This strategy is consistent with the principle of reducing the BD and ED of residential area in this paper, because the increase in these two indicators will reduce the WSR at any height level (N. E. Yuan C, Norford L K, 2012). To sum up, the existence of urban built-up area inevitably reduces the near-surface ventilation efficiency. In response to this, planners and architects need to fully consider the regional meteorological conditions and building morphology.

\section{Conclusions}

Based on one typical determinant residential area, the present paper, through field measurement and numerical simulation method, discusses the influencing factors of the ventilation efficiency at different height levels in the residential area. The main conclusions are as follows:

1) The mean WS measured below $35 \mathrm{~m}$ in residential area and park are $1.2 \mathrm{~m} / \mathrm{s}$ and 1.8 $\mathrm{m} / \mathrm{s}$, respectively. Residential buildings reduce WS by about $0.6 \mathrm{~m} / \mathrm{s}$. This shows that the presence of residential buildings greatly reduces the inflow of wind. Thus, is particularly important to optimize the layout of residential buildings to let more winds in.

2) The results of single factor analysis show that the mean WSR at the pedestrian height level has a negative correlation with each of the indicators studied.

3) The results of multi-factor analysis show that the ventilation performance at different heights is positively related to the building height and the MBH. The HF has the greatest influence on the WSR at all heights in the residential area. This indicates that to improve the ventilation efficiency among buildings, the height difference should be minimized.

4) The research can provide data support for the establishment and improvement of wind 
environment standards in residential areas, and provide a reference method for optimizing the ventilation efficiency in different regions, especially in static wind areas

Funding The study was supported by NSFC General Project (grant number 51808440), and the Opening Fund of Key Laboratory of Interactive Media Design and Equipment Service Innovation, Ministry of Culture and Tourism（grant number 20205）.

Author contributions Wei Feng and Meng Zhen designed the experiments, Qishu Zou carried out field measurement, Wei Ding ran simulations, analyzed the results, and wrote the manuscript. The authors read and approved the final manuscript.

\section{Declarations}

Ethics approval and consent to participate Not applicable.

Consent for publication All the authors have read and approved the manuscript for publication.

Competing interests The authors declare no competing interests.

Data availability Data will be sent based on request.

\section{References}

Á., S. (2013). Wind comfort in a public urban space-case study within Dublin Docklands. Frontiers of architectural Research, 2(1): 50-66.

Adamek K, V. N., Elshaer A, et al. . (2017). Pedestrian level wind assessment through city development: A study of the financial district in Toronto. Sustainable Cities and Society, 35: 178-190.

Bruse, M., Fleer, H. J. E. M., \& Software. (1998). Simulating surface-plant-air interactions inside urban environments with a three dimensional numerical model. 13(3-4), 373-384.

Du Y, M. C. M., Liu J, et al. . (2017). Effects of lift-up design on pedestrian level wind comfort in different building configurations under three wind directions. Building and Environment, 117: 84-99. 
E., L. H. (1981). The urban climate: Academic press.

Feng W, D. W., Fei M, et al. . (2020). Effects of traditional block morphology on wind environment at the pedestrian level in cold regions of Xi'an, China. Environment, Development and Sustainability, 1-18.

FL., W. (2005). The Beaufort Wind Scale.

Grimmond C S B, O. T. R. (1999). Aerodynamic properties of urban areas derived from analysis of surface form. Journal of applied meteorology, 38(9): 1262-1292.

Hong B, L. B. (2015). Numerical studies of the outdoor wind environment and thermal comfort at pedestrian level in housing blocks with different building layout patterns and trees arrangement. Renewable Energy, 73: 18-27.

Jin LN, Q. J., Geng Y, et al. (2014). Comprehensive Analysis of Climate Change Characteristics in Xi'an in Recent 63 Years. Shaanxi Meteorology, (03): 17-20.

Jones P J, A. D., Burnett J. . (2004). Pedestrian wind environment around high-rise residential buildings in Hong Kong. Indoor and Built Environment, 13(4): 259-269.

Jung W S, P. J. K., Lee H W. . (2006). An analysis on influence of geographical variation induced by development affecting to the local scale wind environment-numerical simulation using the Envi-met model. Journal of Korean Society for Atmospheric Environment, 22(6): 888-903.

Kubota T, M. M., Tominaga Y, et al. (2008). Wind tunnel tests on the relationship between building density and pedestrian-level wind velocity: Development of guidelines for realizing acceptable wind environment in residential neighborhoods. Building and Environment, 1699-1708. 43(10): 1699-1708.

Kubota T, M. M., Tominaga Y, et al. 1699-1708. (2008). Wind tunnel tests on the relationship between building density and pedestrian-level wind velocity: Development of guidelines for realizing acceptable wind environment in residential neighborhoods. Building and Environment,, 43(10): .

Li L, Y. X., Qian Y. . (2018). CFD Simulation Analysis of the Influence of Floor Area Ratio on the Wind Environment in Residential Districts. Journal of Engineering Science \& Technology Review, 11(5).

Liu, J. (2011). Urban physical environment: China Building Industry Press. 
Liu S, P. W., Zhang H, et al. . (2017). CFD simulations of wind distribution in an urban community with a full-scale geometrical model. Building and Environment,, 117: 11-23.

Ministry of housing and urban-rural development, P. (2012). Design specification for heating, ventilation and air conditioning in civil buildings GB.50736-2012. Beijing: China standard press.

Mittal H, S. A., Gairola A. . (2019). Numerical simulation of pedestrian level wind flow around buildings: effect of corner modification and orientation. Journal of Building Engineering, 22: 314-326.

Mochida A, L. I. Y. F. (2008). Prediction of wind environment and thermal comfort at pedestrian level in urban area. Journal of Wind Engineering and Industrial Aerodynamics, 96(10-11): 1498-1527.

Ng E, Y. C., Chen L, et al. . (2011). Improving the wind environment in high-density cities by understanding urban morphology and surface roughness: a study in Hong Kong. Landscape and Urban planning,, 101(1): 59-74.

Ren Chao, W. E., Ye Songwen, Zheng Shiyou. (2017). Climatic-spatial planning and design in high density cities: an implementation and practical experience of hong kong air ventilation assessment. Urbanism and Architecture, (01):20-23.

S., A. O. (2010). Prediction of wind environment in different grouping patterns of housing blocks. Energy and Buildings, 42(11): 2061-2069.

State bureau of technical supervision, P. M. o. c., PRC. . (2018). Code for planning and design of urban residential areas (2016 edition) (GB50180-93) In. Beijing: China construction industry press.

To A P, L. K. M. (1995). Evaluation of pedestrian-level wind environment around a row of tall buildings using a quartile-level wind speed descripter. Journal of Wind Engineering and Industrial Aerodynamics, 54: 527-541.

Vazquez-Prokopec G M, K. U., Montgomery B, et al. . (2010). Quantify ing the spatial dimension of dengue virus epidemic spread within a tropical urban environment. PLoS neglected tropical diseases, 4(12).

Wang Y, Z. D., Wang Y, et al. . (2019). Comparative study of urban residential design and microclimate characteristics based on ENVI-met simulation. Indoor and Built Environment, 
28(9): 1200-1216.

461 Yang F, Q. F., Lau S S Y. . (2013). Urban form and density as indicators for summertime 462 outdoor ventilation potential: A case study on high-rise housing in Shanghai. Building and 463 Environment, ,70: 122-137.

464 Yang J, S. B., Shi Y, et al. . (2020). Air pollution dispersal in high density urban areas: 465 Research on the triadic relation of wind, air pollution, and urban form. Sustainable Cities and 466 Society, 54: 101941.

467 Yang, J. Z., Tao; Fu Xiuzhang. (2016). Coupling Mechanism between Wind Environment 468 and Space Form and Optimization Design in City Center. Nanjing: Southeast University 469 Press.

470 Yuan C, N. E., Norford L K. (2012). Building porosity for better urban ventilation in 471 high-density cities-A computational parametric study. Building and Environment, 50: $472 \quad 176-189$.

473 Yuan C, N. E., Norford L K. . (2014). Improving air quality in high-density cities by 474 understanding the relationship between air pollutant dispersion and urban morphologies. 475 Building and Environment, 71.245-258. 
Figures

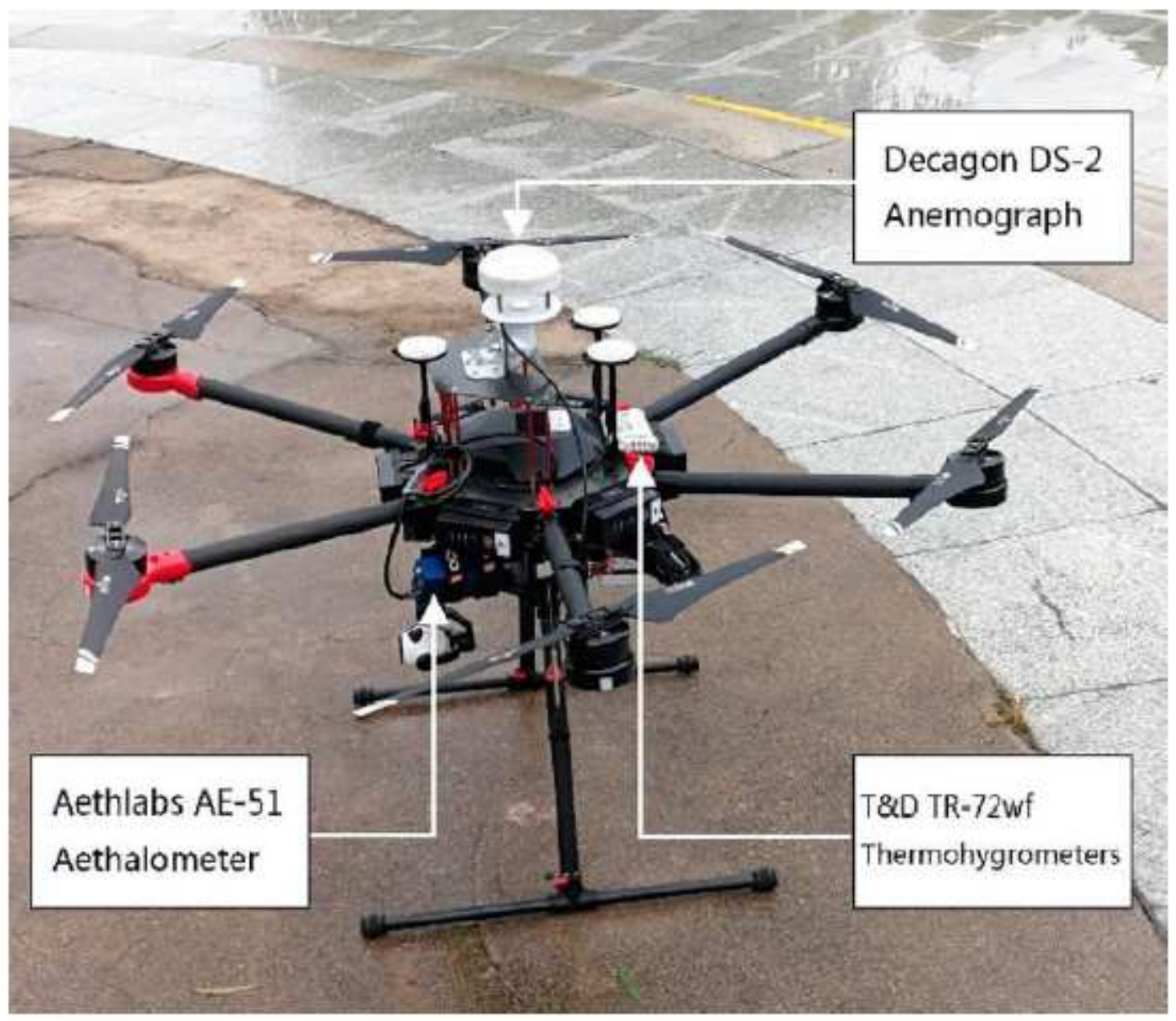

Figure 1

UAV and test equipment (Zhen M, 2019) 


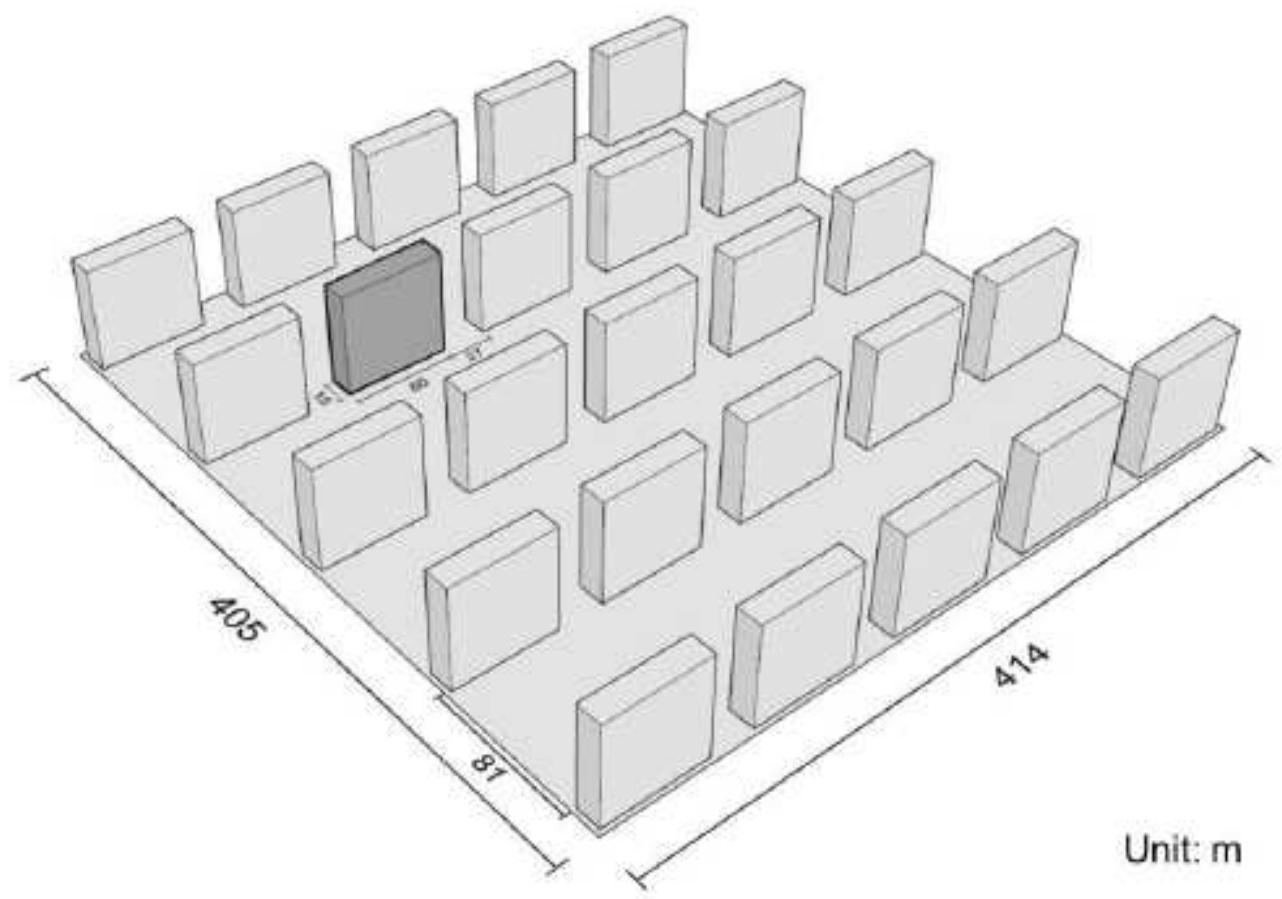

Figure 2

Basic model

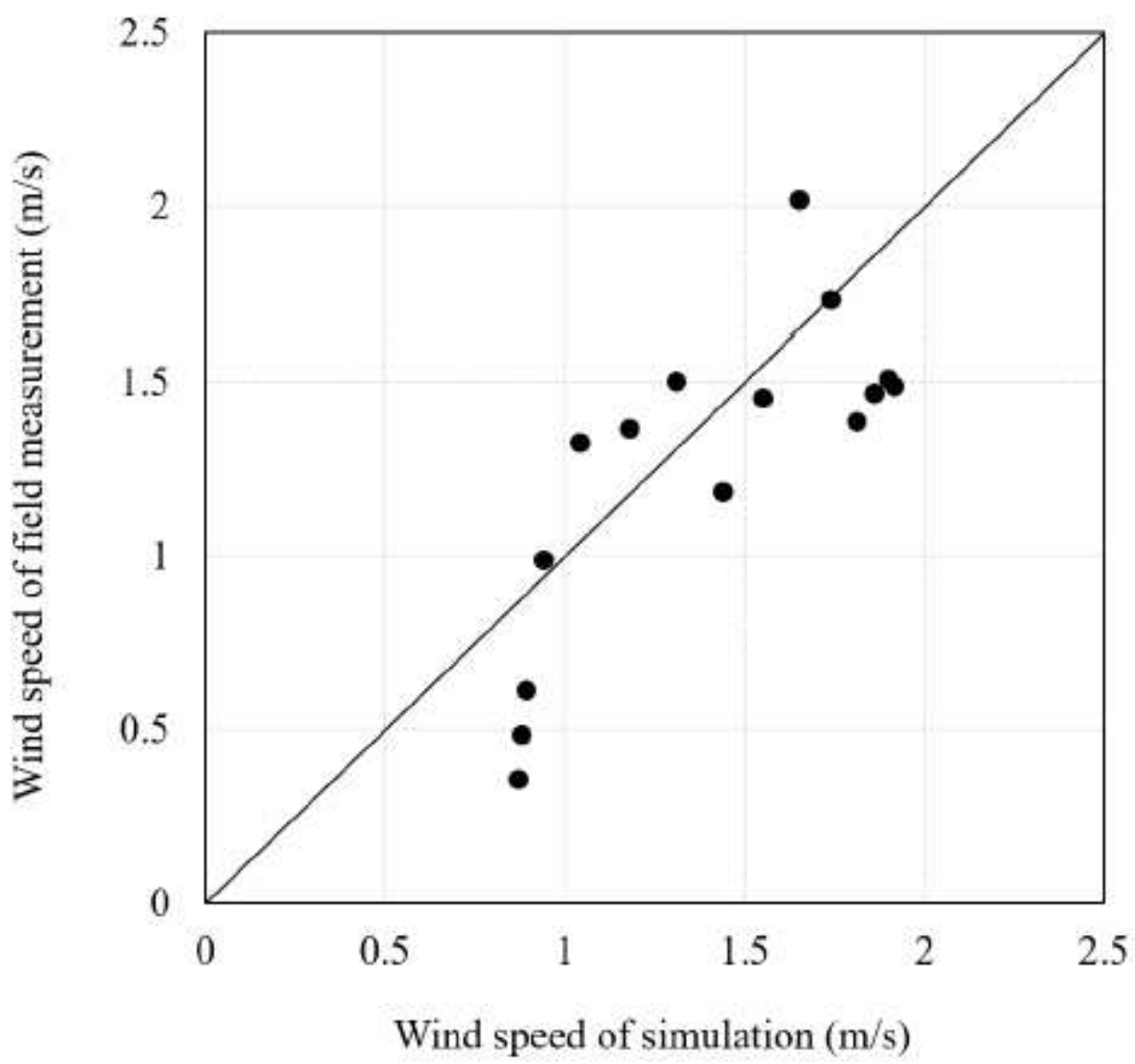


Figure 3

Correlation between measured and simulated results of vertical WS

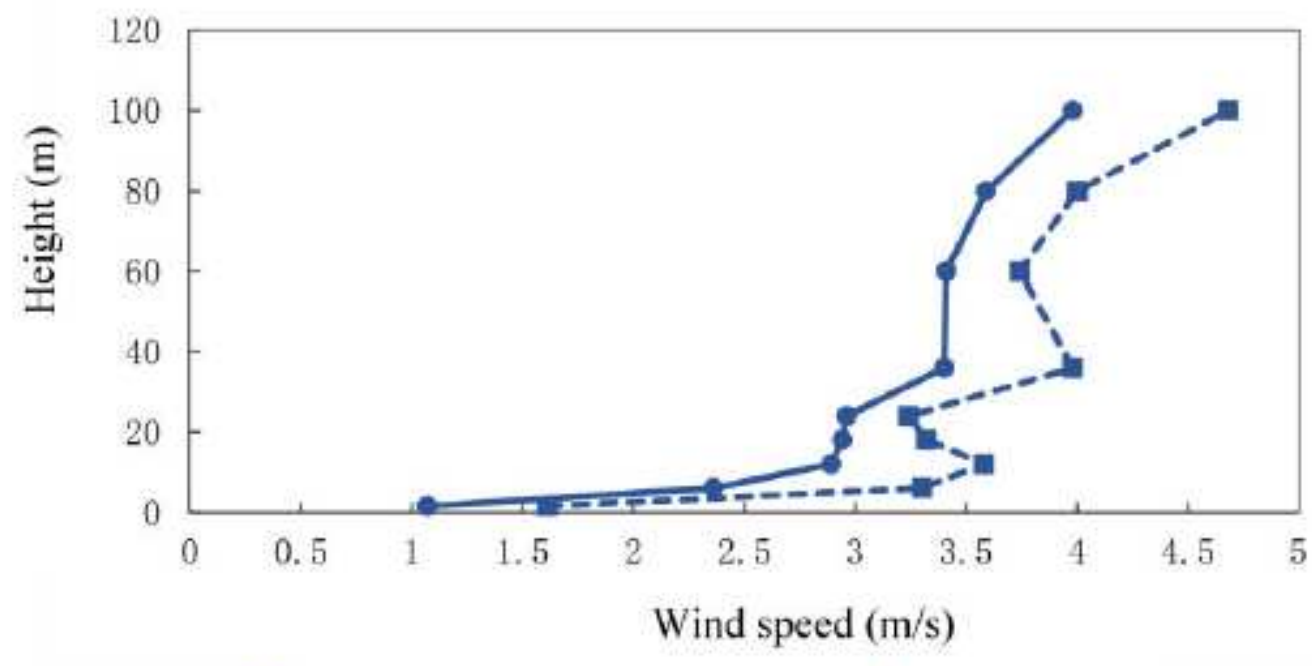

$-m$ - Maximum wind speed $\quad \rightarrow$ Mean wind speed

\section{Figure 4}

The WS at different heights in Zishui Park in Xi'an

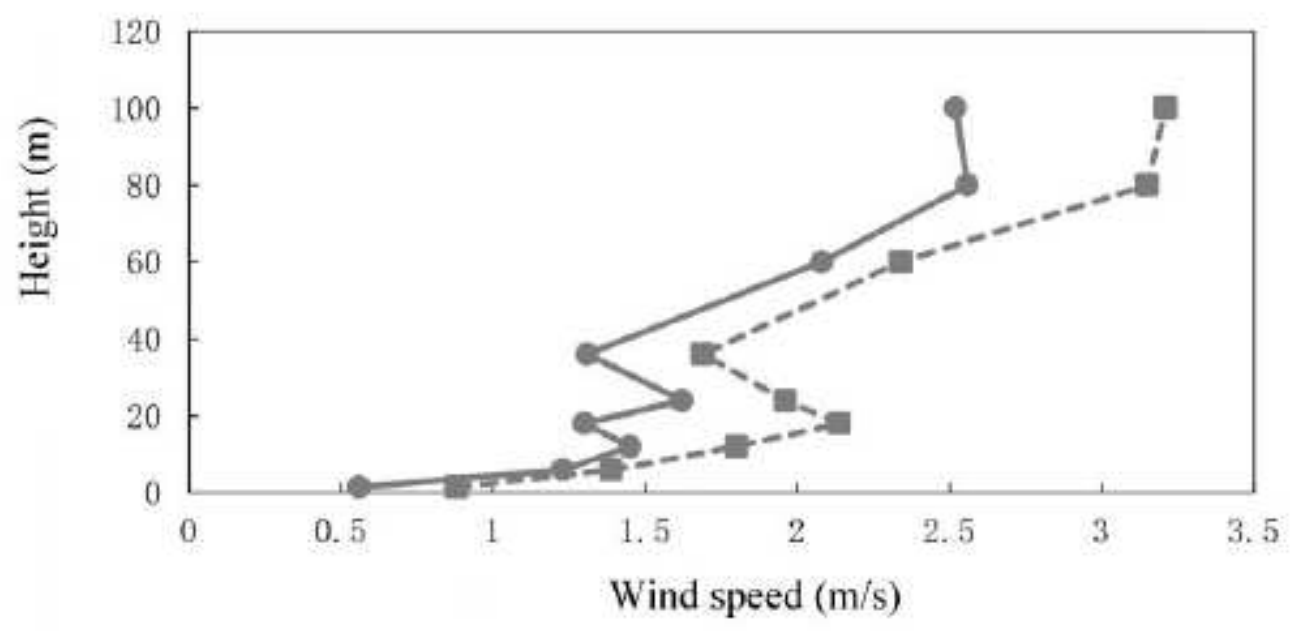

- - - Maximum wind speed $\rightarrow$ Mean wind speed

\section{Figure 5}

The WS at different heights at Shijiaxingcheng in Xi'an 


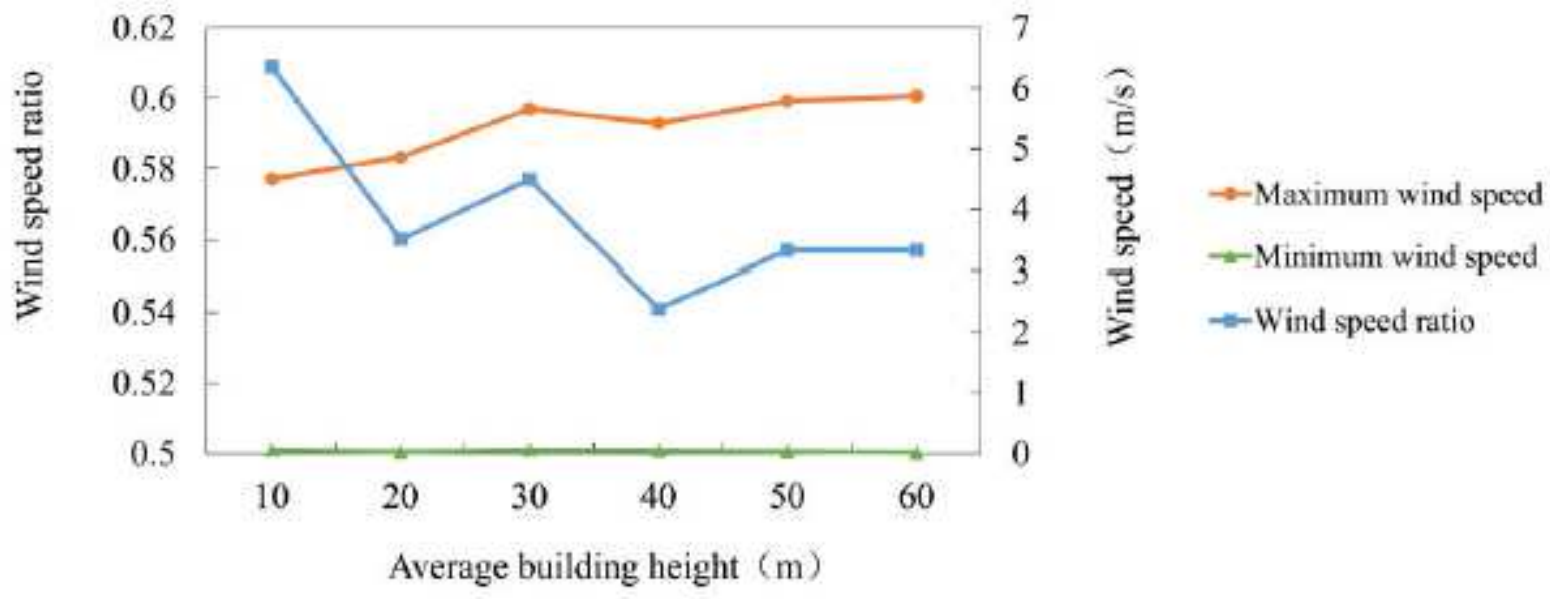

Figure 6

Correlation between mean WSR and ABH

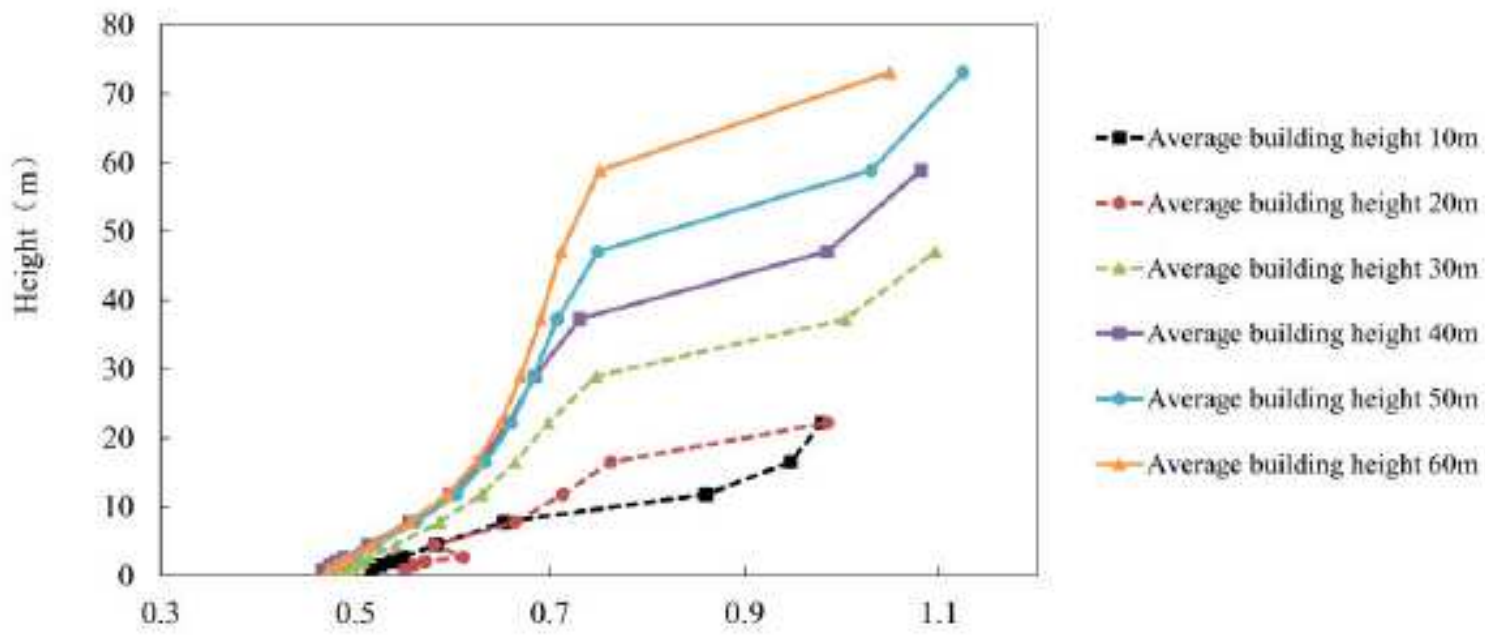

Mean wind speed ratio

Figure 7

Correlation between the $\mathrm{ABH}$ and the mean WSR in the vertical direction 


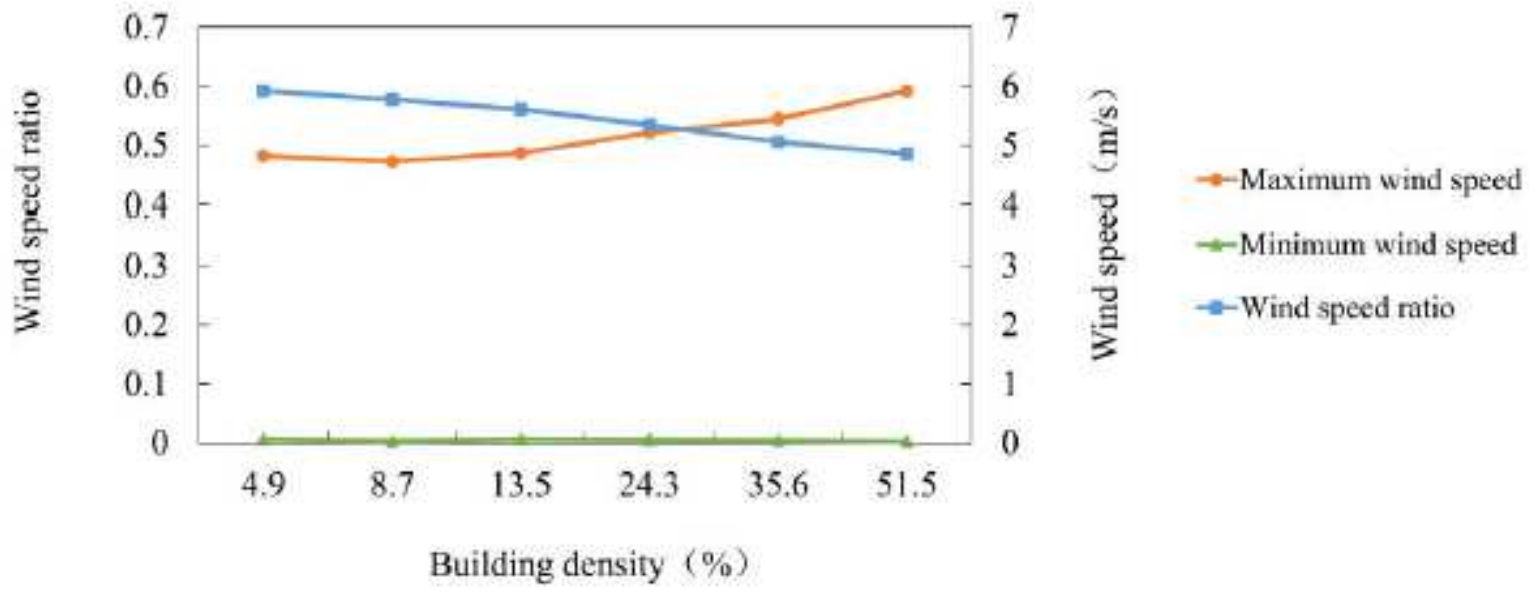

\section{Figure 8}

Correlation between the mean WSR at the pedestrian level and BD

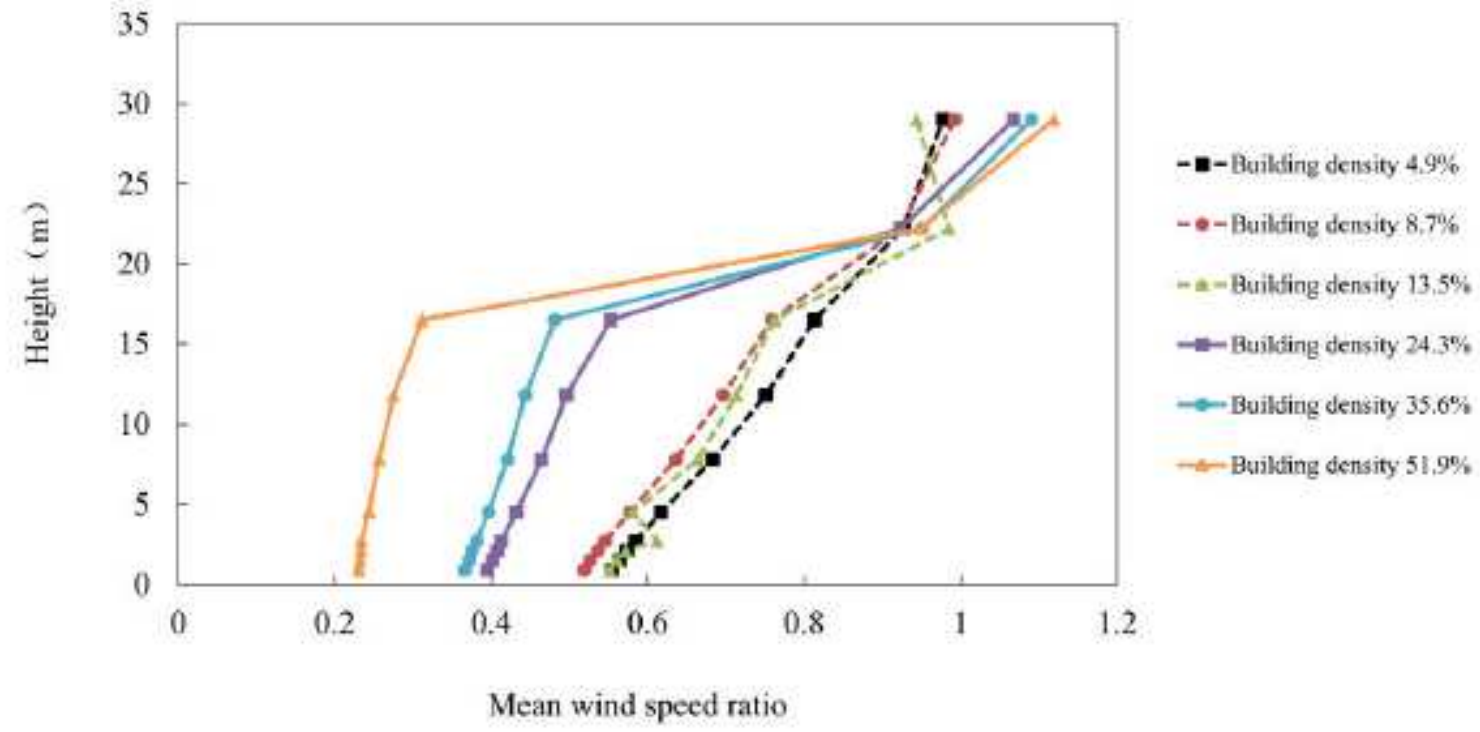

\section{Figure 9}

Variation curve between different BD and mean WSR in the vertical direction 


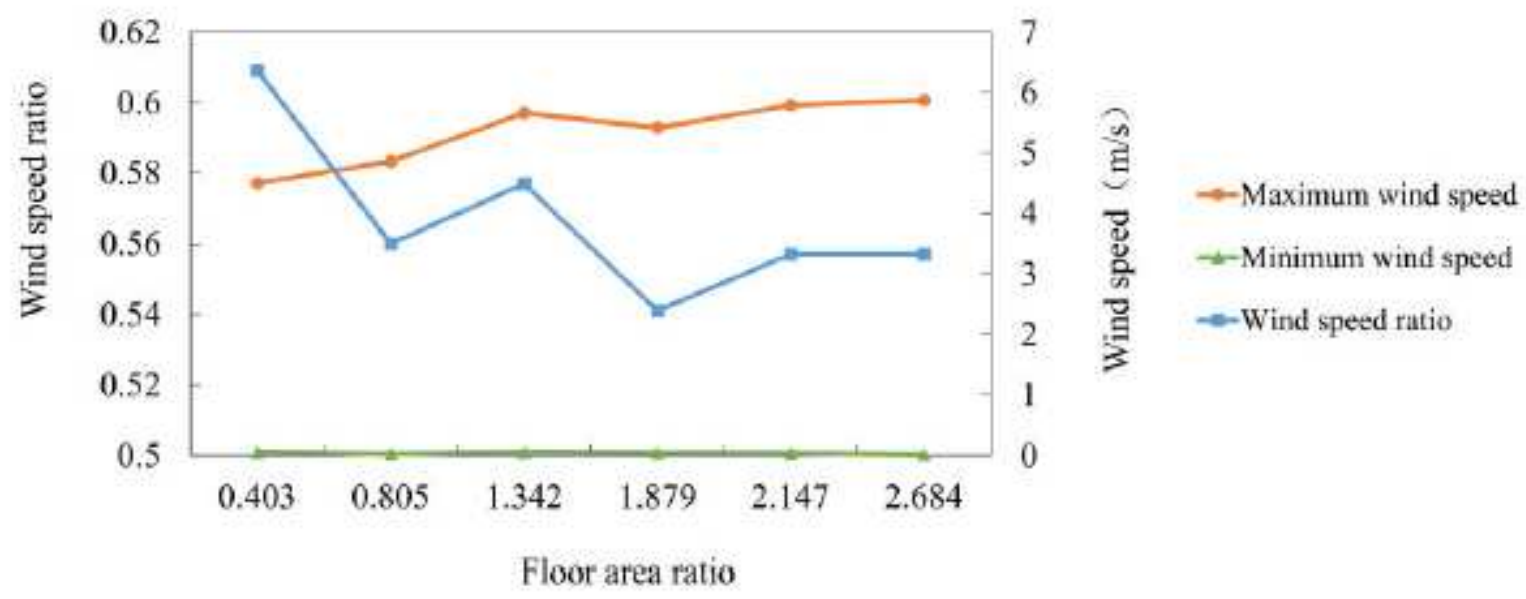

Figure 10

Correlation between mean WSR at the pedestrian level and FAR

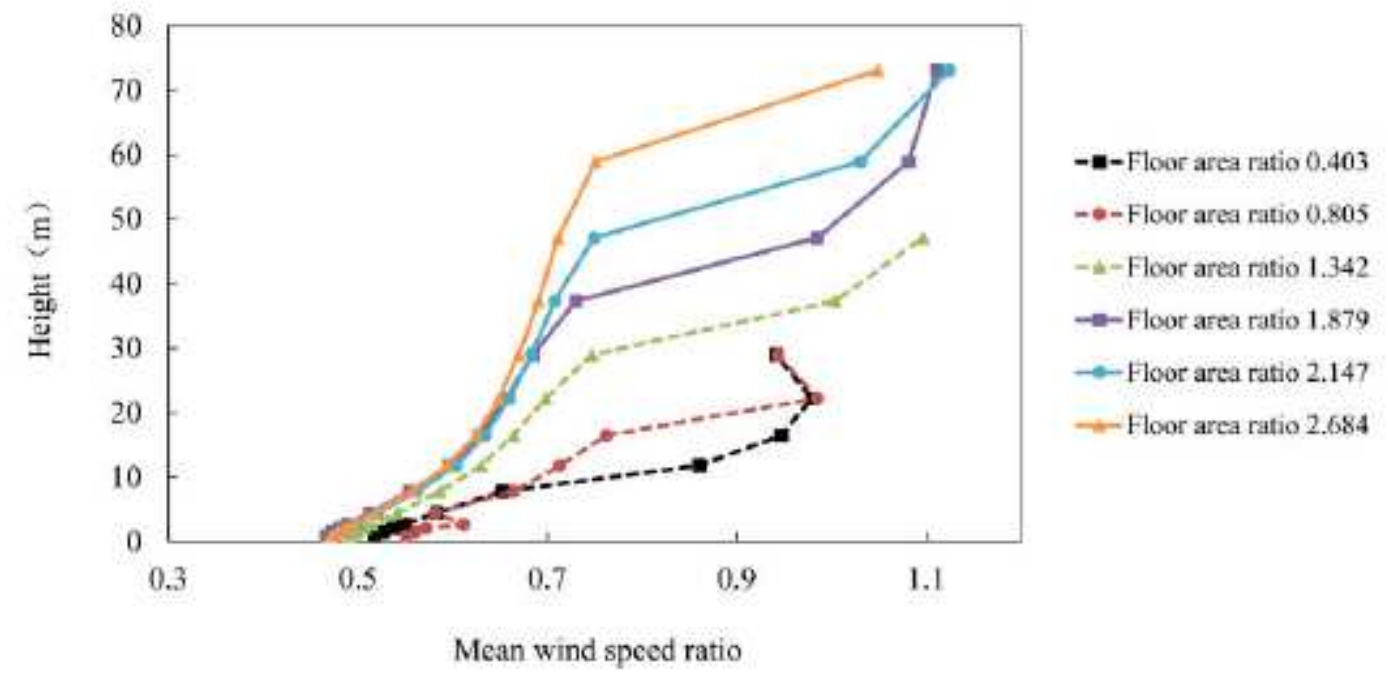

Figure 11

Correlation between the change of FAR with the average height and the mean WSR 


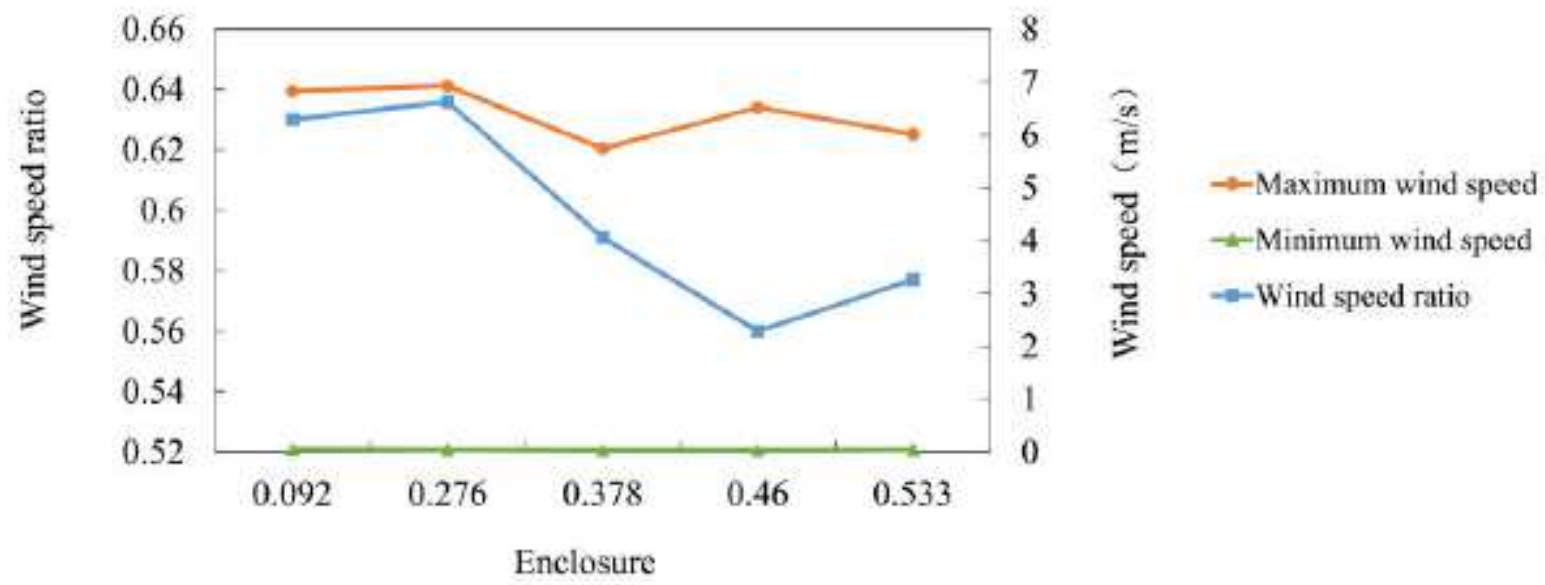

Figure 12

Correlation between the mean pedestrian level WSR and ED

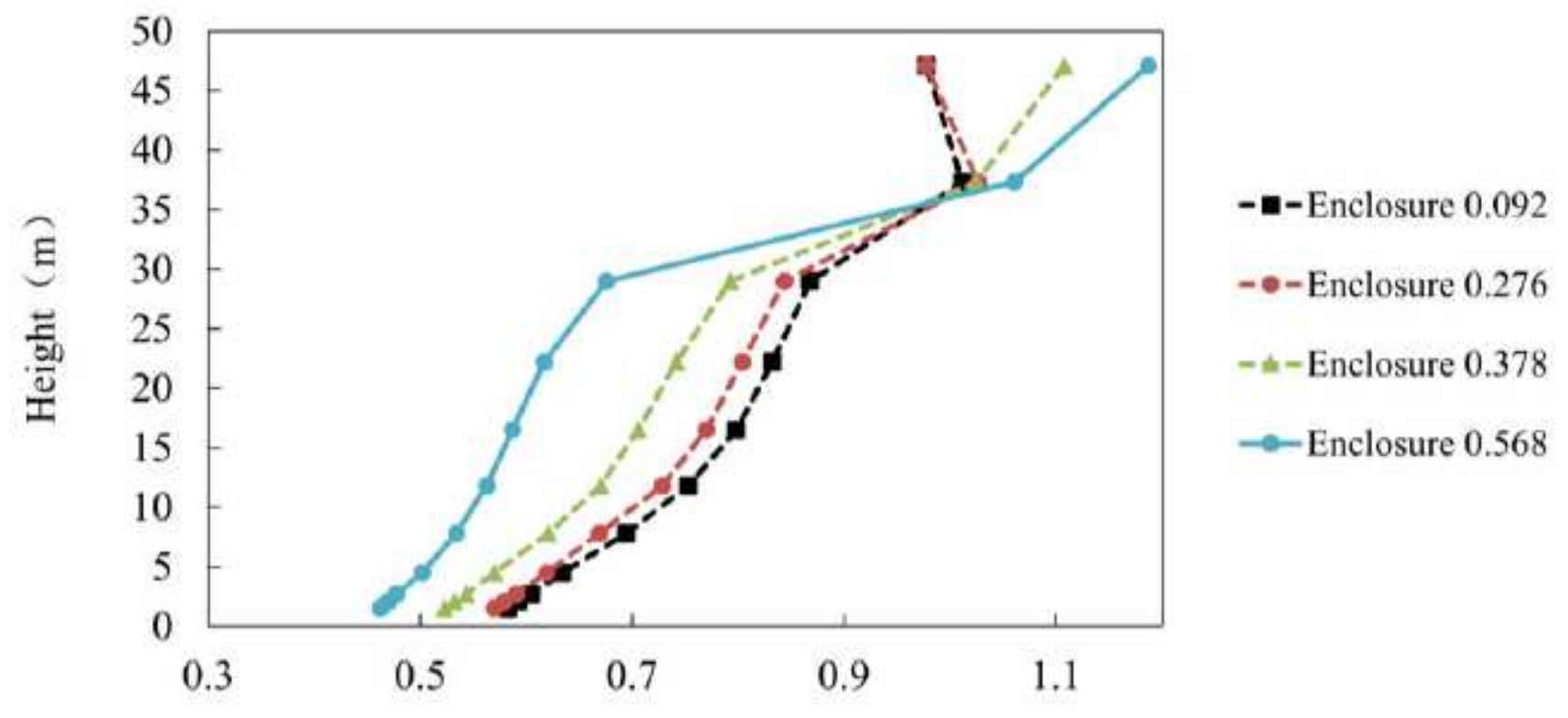

Mean wind speed ratio

Figure 13

Correlation between the mean WSR and different EDs in the vertical direction 


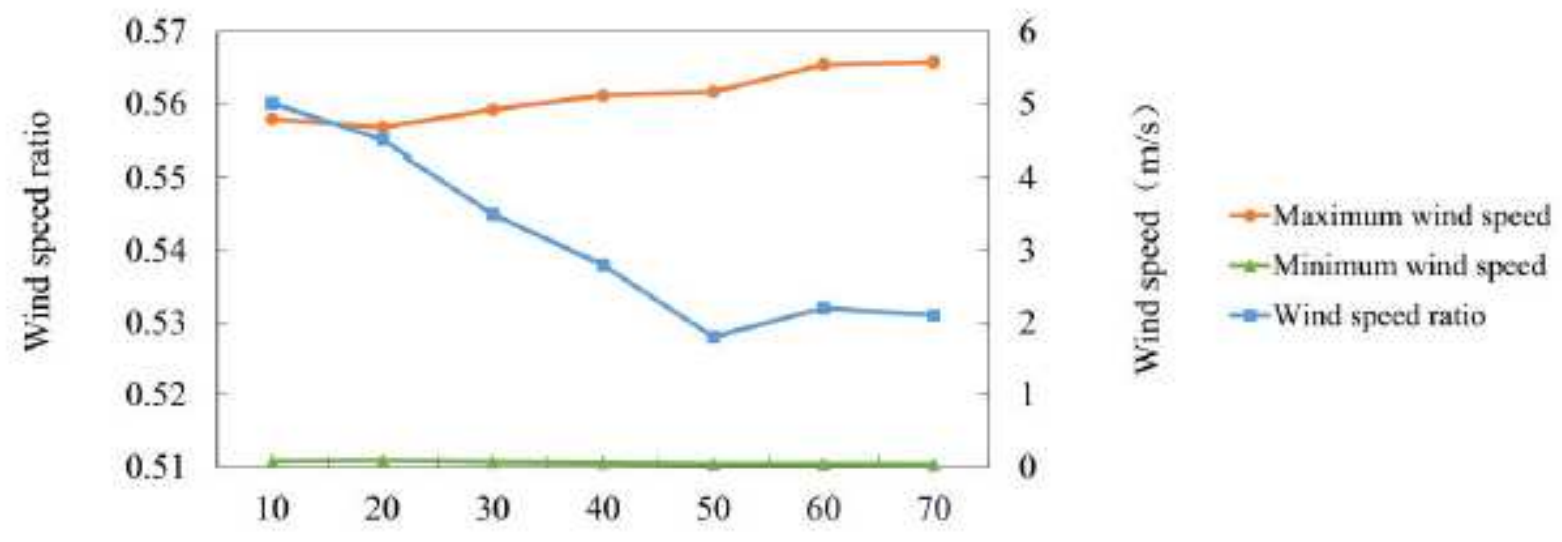

Height fall

\section{Figure 14}

Correlation between the mean WSR at the pedestrian level and HF

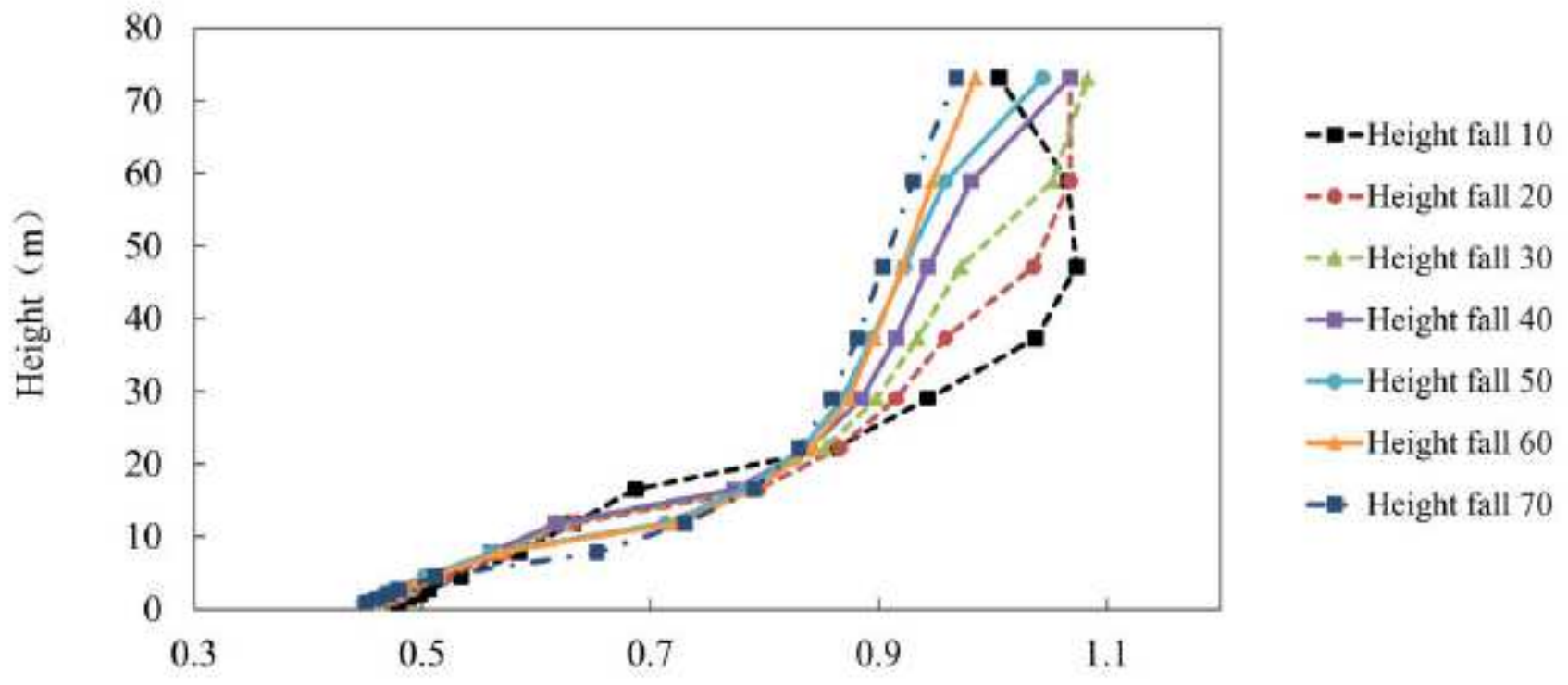

Mean wind speed ratio

Figure 15

Correlation between the mean WSR and different HF in the vertical direction 


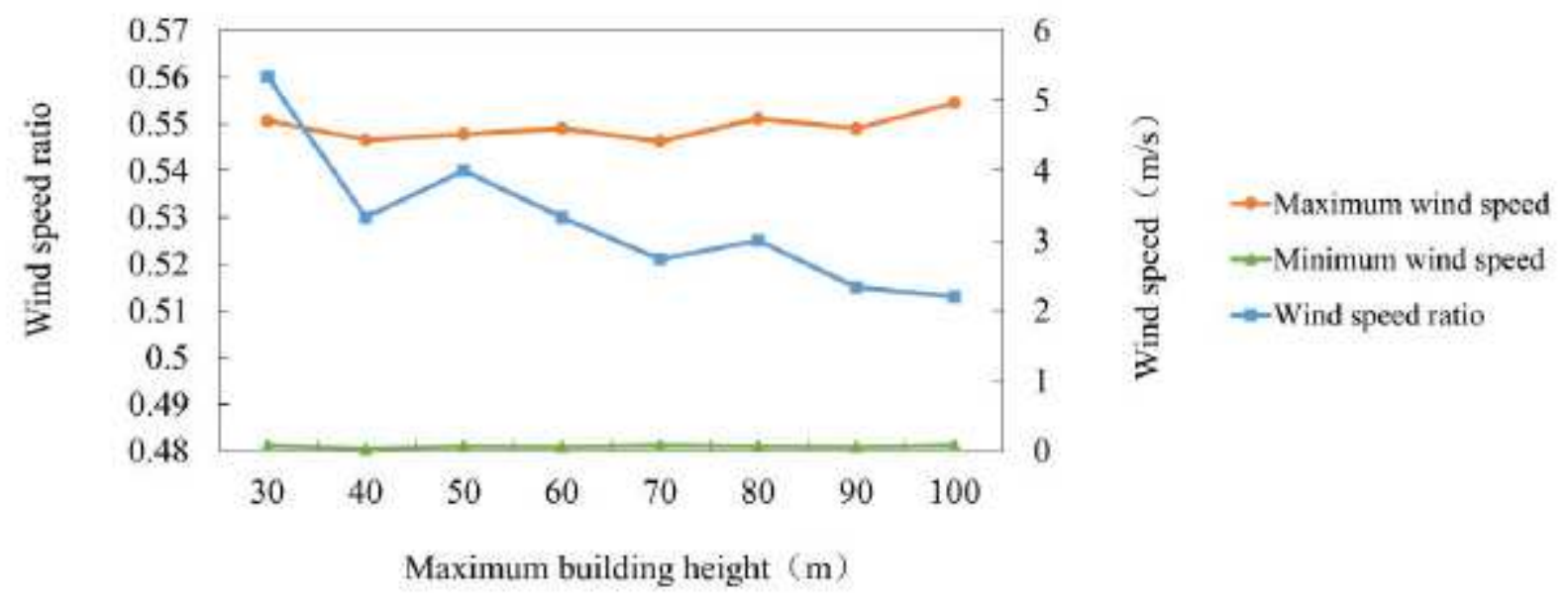

\section{Figure 16}

Correlation between the mean WSR at the pedestrian level and MBH

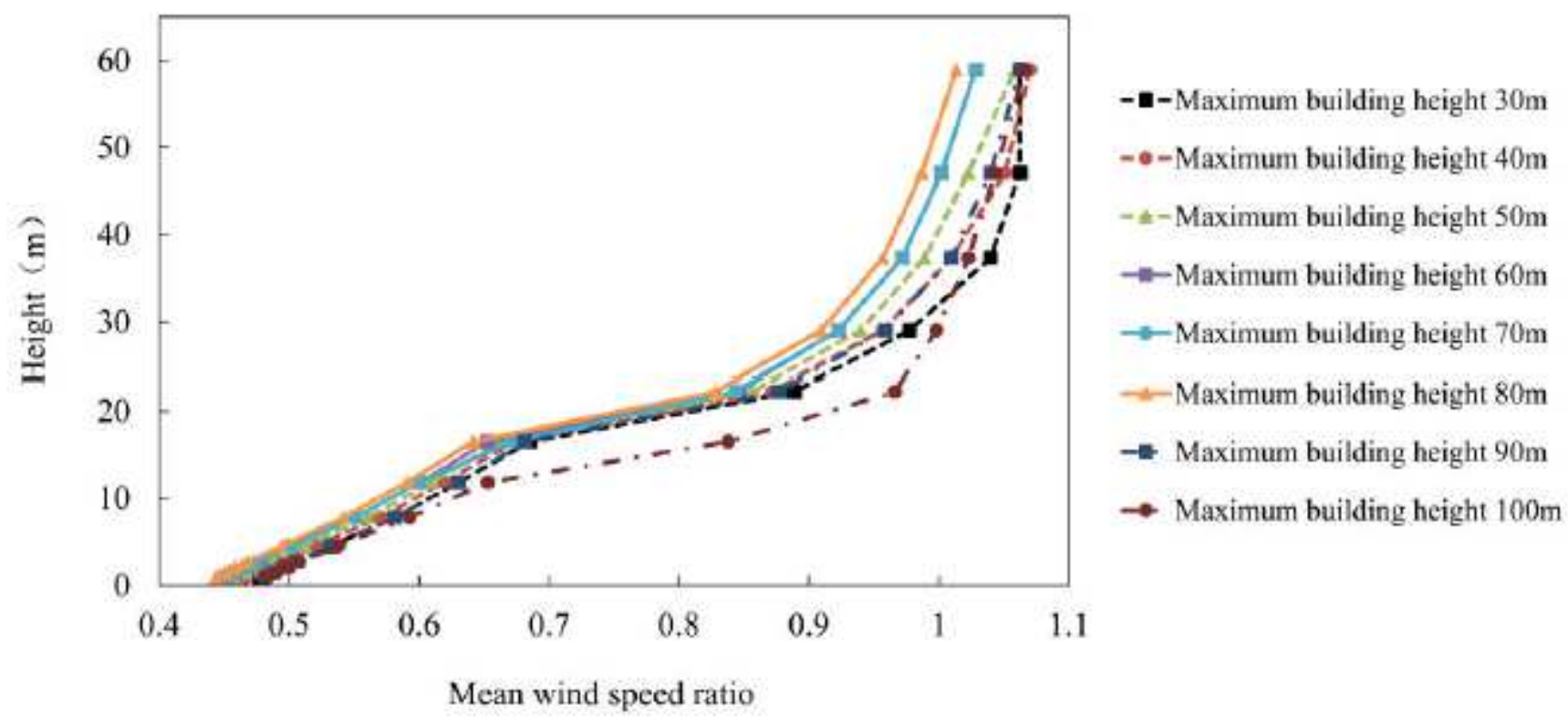

Figure 17

Correlation between the MBH and the mean WSR of different sites in the vertical direction 